\title{
The effect of gas permeation through vertical membranes on chemical switching reforming (CSR) reactor performance
}

\section{Citation for published version (APA):}

Wassie, S. A., Gallucci, F., Cloete, S., Zaabout, A., van Sint Annaland, M., \& Amini, S. (2016). The effect of gas permeation through vertical membranes on chemical switching reforming (CSR) reactor performance. International Journal of Hydrogen Energy, 41(20), 8640-8655. https://doi.org/10.1016/j.ijhydene.2015.12.003

\section{Document license:}

TAVERNE

DOI:

10.1016/j.ijhydene.2015.12.003

Document status and date:

Published: 01/01/2016

\section{Document Version:}

Publisher's PDF, also known as Version of Record (includes final page, issue and volume numbers)

\section{Please check the document version of this publication:}

- A submitted manuscript is the version of the article upon submission and before peer-review. There can be important differences between the submitted version and the official published version of record. People interested in the research are advised to contact the author for the final version of the publication, or visit the $\mathrm{DOI}$ to the publisher's website.

- The final author version and the galley proof are versions of the publication after peer review.

- The final published version features the final layout of the paper including the volume, issue and page numbers.

Link to publication

\section{General rights}

Copyright and moral rights for the publications made accessible in the public portal are retained by the authors and/or other copyright owners and it is a condition of accessing publications that users recognise and abide by the legal requirements associated with these rights.

- Users may download and print one copy of any publication from the public portal for the purpose of private study or research.

- You may not further distribute the material or use it for any profit-making activity or commercial gain

- You may freely distribute the URL identifying the publication in the public portal.

If the publication is distributed under the terms of Article 25fa of the Dutch Copyright Act, indicated by the "Taverne" license above, please follow below link for the End User Agreement:

www.tue.nl/taverne

Take down policy

If you believe that this document breaches copyright please contact us at:

openaccess@tue.nl

providing details and we will investigate your claim. 


\title{
The effect of gas permeation through vertical membranes on chemical switching reforming (CSR) reactor performance
}

\author{
Solomon Assefa Wassie ${ }^{a, c}$, Fausto Gallucci ${ }^{c}$, Schalk Cloete ${ }^{b}$, \\ Abdelghafour Zaabout ${ }^{b}$, Martin van Sint Annaland ${ }^{c}$, Shahriar Amini ${ }^{a, b, *}$ \\ a Norwegian University of Science and Technology, Department of Energy and Process Engineering, Trondheim, \\ Norway \\ b SINTEF Materials and Chemistry, Flow Technology Department, Trondheim, Norway \\ ${ }^{c}$ Chemical Process Intensification, Eindhoven University of Technology, Department of Chemical Engineering and \\ Chemistry, Eindhoven, The Netherlands
}

\section{A R T I C L E I N F O}

Article history:

Received 15 September 2015

Received in revised form

17 November 2015

Accepted 3 December 2015

Available online 8 January 2016

Keywords:

Fluidized bed

Chemical switching reforming

Membrane configurations

Hydrogen production

\begin{abstract}
A B S T R A C T
A novel membrane assisted fluidized bed reactor concept has been proposed for ultra-pure hydrogen production with integrated $\mathrm{CO}_{2}$ capture from steam methane reforming. The socalled Chemical Switching Reactor (CSR) concept combines the use of an oxygen carrier for supplying heat and catalysing the steam methane reforming reaction and hydrogen permselective membrane (thin Pd-membrane) for hydrogen recovery. However, extraction of gas through the membranes influences the hydrodynamics of the fluidized bed by altering the bubble behaviour and the extent of gas back mixing. Bubble properties (size, number and velocity) strongly influence the performance of fluidized bed reactors as they play a major role in heat and mass transfer phenomena. This work experimentally investigates the effects of gas extraction via vertical membranes on the bubble properties using Digital Image Analysis (DIA) technique and numerically using the Two Fluid Model approach (TFM) closed by the kinetic theory of granular flow. The simulation studies were extended to investigate real reactive conditions. A pseudo 2D experimental setup with a multichamber porous plate mounted at the bottom of the back plate was used to simulate vertical membranes. This setup allowed for gas extraction in specific locations from the back of the column, thus facilitating studies on the effect of gas extraction rates and locations on the bubble properties. Results show that variation of gas extraction flow rates slightly influences the bubble behaviour, whereas variation of gas extraction locations (varying the area) significantly influences bubble properties. Cold flow simulations showed a reasonable comparison to experimental measurements and reactive simulations revealed very similar hydrodynamic responses to changes in gas extraction rate (membrane permeability) and location. Shifting gas extraction towards the centre of the bed proved to be beneficial in reducing gas back-mixing. Specifically, reducing the number of vertical membranes from 7 to 5 by removing the outer two membranes showed a slight increase in hydrogen extraction performance.
\end{abstract}

๑ 2015 Hydrogen Energy Publications LLC. Published by Elsevier Ltd. All rights reserved.

\footnotetext{
* Corresponding author.

E-mail address: shahriar.amini@sintef.no (S. Amini). 


\begin{tabular}{|c|c|c|c|}
\hline \multicolumn{2}{|c|}{ List of symbols } & $k_{1}$ & reaction rate constant, $\mathrm{mol} \mathrm{bar} \mathrm{b}^{0.5} / \mathrm{kg}_{\mathrm{Ni}} \mathrm{s}$ \\
\hline \multicolumn{2}{|c|}{ Main symbol definitions } & $k_{3}$ & $\begin{array}{l}\text { reaction rate constant, } \mathrm{mol} / \mathrm{bar}_{\mathrm{kg}}^{\mathrm{Ni}} \mathrm{S} \\
\text { reaction rate constant, } \mathrm{mol} \mathrm{bar}^{0.5} / \mathrm{kg}_{\mathrm{Ni}} \mathrm{S}\end{array}$ \\
\hline$\alpha$ & volume fraction & $P$ & permeability, $\mathrm{mol} \mathrm{s} \mathrm{-}^{-1} \mathrm{~m}^{-1} \mathrm{~Pa}^{-\mathrm{n}}$ \\
\hline$\phi$ & kinetic energy transfer rate, $\mathrm{kg} / \mathrm{m} \mathrm{s}^{3}$ & $p$ & pressure, $\mathrm{Pa}$ \\
\hline$\gamma$ & dissipation rate, $\mathrm{kg} / \mathrm{m} \mathrm{s}^{3}$ & $r_{1}, r_{2}, r_{3}$ & reaction rate, $\mathrm{mol} / \mathrm{s} \mathrm{kg}_{\mathrm{Ni}}$ \\
\hline$\Theta_{S}$ & granular temperature, $\mathrm{m}^{2} / \mathrm{s}^{2}$ & S & species source term, $\mathrm{kg} / \mathrm{m}^{3} \mathrm{~s}$ \\
\hline$\rho$ & density, $\mathrm{kg} / \mathrm{m}^{3}$ & $\mathrm{~T}$ & temperature, $\mathrm{K}$ \\
\hline$\overline{\bar{\tau}}$ & stress tensor, $\mathrm{kg} / \mathrm{m} \mathrm{s}^{2}$ & $t_{\text {mem }}$ & membrane thickness, $\mathrm{m}$ \\
\hline$\vec{v}$ & velocity vector, $\mathrm{m} / \mathrm{s}$ & $t$ & time, $\mathrm{s}$ \\
\hline$\nabla$ & del operator/Gradient, 1/m & $\overrightarrow{\mathrm{U}}_{s, \|}$ & slip velocity parallel to the wall, $\mathrm{m} / \mathrm{s}$ \\
\hline C & membrane permeability adjustment constant & Y & species mass fraction \\
\hline & activation energy, kJ/mol & \multirow{2}{*}{\multicolumn{2}{|c|}{ Subscript definitions }} \\
\hline$\vec{g}$ & gravity vector, $\mathrm{m} / \mathrm{s}^{2}$ & & \\
\hline$g_{0, s s}$ & radial distribution function & & tional \\
\hline & identity tensor & l & species index \\
\hline$\vec{J}$ & diffusive flux, $\mathrm{kg} / \mathrm{m}^{2} \mathrm{~s}$ & 9 & gas \\
\hline & diffusive flux of hydrogen, $\mathrm{kg} / \mathrm{m}^{2} \mathrm{~s}$ & gs & inter-phase \\
\hline & momentum exchange coefficient, $\mathrm{kg} / \mathrm{m}^{3} \mathrm{~s}$ & q & phase index \\
\hline K & equilibrium constant or adsorption coefficient & $S$ & ids \\
\hline & diffusion coefficient, $\mathrm{kg} / \mathrm{m} \mathrm{s}$ & & \\
\hline
\end{tabular}

\section{Introduction}

According to the IPCC fifth assessment report [1], greenhouse gas emissions (primarily $\mathrm{CO}_{2}$ ) due to the use of fossil fuels as a source of energy have increased in the atmosphere since preindustrial times, and this increase is the main cause of climate change (Chapter 10). Different approaches have been proposed to reduce carbon dioxide emissions to the atmosphere. $\mathrm{CO}_{2}$ Capture and Storage (CCS) is one of the most important of these approaches if long term global temperature rise is to be kept below $2{ }^{\circ} \mathrm{C}$. Chapter 6 of the latest IPCC Report [1] calculates that achieving this aim without CCS would double climate change mitigation costs.

Among the possible technological strategies related to CCS, hydrogen production with integrated $\mathrm{CO}_{2}$ capture under the pre-combustion route is a promising technology in terms of process efficiency [2-5]. Different systems have been proposed under this consideration with auto-thermal Chemical Looping Reforming (CLR) regarded as one of the most promising [2,5-7]. CLR utilizes the same basic principles as Chemical Looping Combustion (CLC); the main difference being that the desired product in CLR is not heat (used to drive a power cycle) but $\mathrm{H}_{2}$ and CO. Similar to CLC, CLR is conventionally carried out in two interconnected fluidized bed reactors, called air and fuel reactors, where an oxygen carrier (metal or metal oxide) transports oxygen from the air to the fuel. This results in inherent separation of $\mathrm{CO}_{2}$ and $\mathrm{N}_{2}$ with a much lower energy penalty than usually associated with conventional $\mathrm{CO}_{2}$ capture processes [8-10].

In the conventional CLR process, natural gas is transformed into syngas through the steam methane reforming reaction after which the outlet stream of the CLR has to be sent to subsequent Water Gas Shift (WGS) reactors and Pressure Swing Adsorption (PSA) unit if pure $\mathrm{H}_{2}$ is the desired endproduct $[11,12]$. This technology provides an important improvement as auto-thermal operation can be achieved in the CLR as opposed to a high external heat demand required in traditional Steam Methane Reforming (SMR) reactors [5]. However, these three steps can conceivably be integrated into one if hydrogen perm-selective membranes are introduced into the reactor resulting in a thermodynamically favourable process $[5,13]$. This high level of process intensification can lead to substantial benefits in terms of efficiency and economics.

The resulting highly intensified membrane-assisted CLR process can potentially be further improved by eliminating the complexities of solids circulation between reactors, especially at higher pressures. High pressure operation would be very important for the membrane assisted-CLR process in order to 1) increase the driving force across the membrane and thereby reduce the amount of membrane surface area required for a given fuel throughput and 2) deliver a high pressure $\mathrm{CO}_{2}$ stream for efficient compression, transport and storage and 3) allow more homogeneous fluidization with better mass transfer rates [14]. In order to allow for relatively easy pressurization and process scale-up, it is therefore proposed that the CLR process be carried out in a single reactor where the oxygen carrier/catalyst is alternatively exposed to fuel and air streams. This concept has recently been experimentally demonstrated [15] and thermodynamically assessed [16] for CLC application and should be directly extendable to the CLR process. In the next section a more detailed 
description of this novel reactor concept and a general introduction of membrane assisted fluidized beds are presented.

\section{Chemical switching reforming (CSR) reactor}

CSR is a novel reactor concept which integrates hydrogen production from SMR and $\mathrm{CO}_{2}$ separation in a single process unit. This concept utilizes hydrogen perm-selective membranes immersed in a fluidized bed reactor to directly recover pure hydrogen produced during steam-methane reforming. Thus it offers: 1) excellent separation properties of membranes (pure hydrogen production coupled with a favourable shift in reaction equilibria), 2) advantages of fluidized bed reactors (excellent heat and mass transfer characteristics), 3) total reactor volume and downstream process units reduction and 4) lower temperature operation (reduces capital costs and heat losses).

A CSR reactor operates in a transient manner with periodic switching in the feed gasses; fuel/steam and air feeds are alternated into a single reactor with a bed of oxygen carrier material which acts both as a catalyst and a heat carrier to the endothermic reforming reaction (Fig. 1). When air is fed to the reactor, the oxygen carrier is heated by the exothermic solids oxidation reaction. This heat is then utilized in the fuel stage where endothermic reduction and catalytic reactions regenerate the oxygen carrier and produce syngas. The periodic switching inherently avoids contact between $\mathrm{CO}_{2}$ and $\mathrm{N}_{2}$, thereby resulting in intrinsic $\mathrm{CO}_{2}$ separation. Recovery of the produced hydrogen from the reactor shifts the steam reforming and water-gas shift reaction equilibria towards complete conversion at intermediate temperatures $\left(500-700{ }^{\circ} \mathrm{C}\right.$, according to the membrane stability at these temperatures) [5], thus resulting in higher reactant conversions and product yields.

In this proposed process, the two main factors which have a major influence on the reactor process performance are membrane permeability and catalytic activity of the oxygen carrier. Consequently, in this work, a preliminary demonstration of the CSR concept is presented in terms of reactor

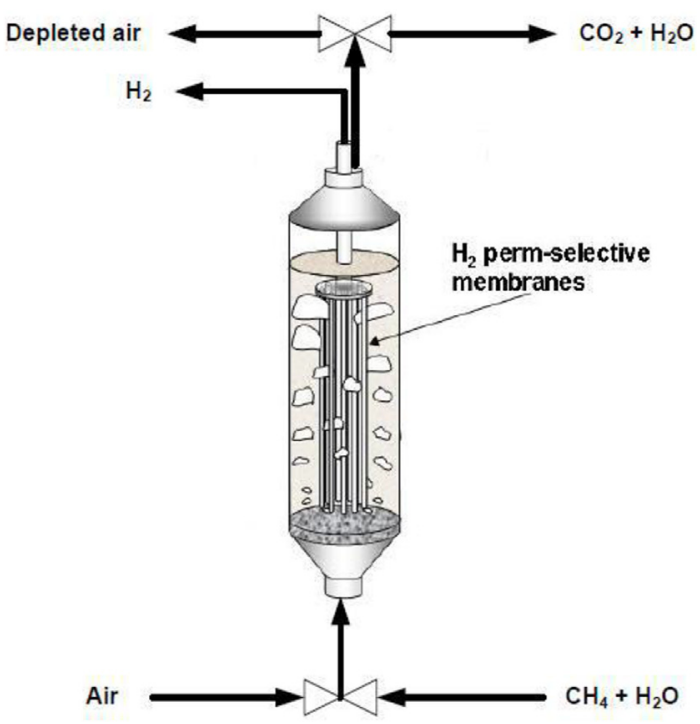

Fig. 1 - Schematic drawing of the CSR system. performance using numerical and experimental hydrodynamic studies.

\section{Studies on membrane-assisted fluidized bed reactors}

Selective removal of products via membranes in fluidized bed reactors has been extensively studied in the last few decades and remains a very active research area. Adris et al. [17-19] was the first to demonstrate selective removal of hydrogen in a fluidized bed reactor from steam methane reforming using palladium membranes. Since then, dozens of studies followed combining phenomenological models and experimental works (e.g. Grace et al. [20], C. S. Patil et al. [21], Chen et al. [22], Gallucci et al. [13], Fernandez, E., et al. [23,24], Medrano et al. [25]) have shown that membrane assisted fluidized bed reactors outperform fluidized bed reactors without membranes and other conventional reactors (increased $\mathrm{CH}_{4}$ conversion, decreased $\mathrm{CO}$ selectivity and higher product selectivity.

Many characteristic features of fluidized bed membrane reactors greatly depend on the hydrodynamics of the reactors and therefore, detailed knowledge of effects of internals, particularly the effects of gas extraction through immersed membranes is essential for the process design and scale-up. Bubble shapes, sizes, numbers, their motion and spatial distribution govern the hydrodynamics and therefore heat and mass transfer, consequently overall rector performance. Therefore, comprehensive knowledge on the effects of the presence of inserted membranes and extraction of some of the fluidizing gas via membranes on the fluidized bed hydrodynamics is of high importance.

De Jong et al. [26] experimentally studied the effect of gas permeation (extraction/addition) through flat membranes on the hydrodynamics of membrane assisted gas-solid fluidized bed. With a combination of Particle Image Velocimetry (PIV) and Digital Image Analysis (DIA) experimental techniques, they found that gas extraction via membranes on the side walls resulted in slightly larger equivalent bubble diameter. This was because of semi-stagnant zones which formed in the vicinity of the membranes and forced bubbles towards the centre of the bed, thus resulting in enhanced bubble coalescence. On the other hand, addition of secondary gas via membranes resulted in a smaller equivalent bubble diameter due to inversion of solid circulation. De Jong et al. [27] extended this study by investigating experimentally the effects of the presence of, and permeation of gas via horizontally immersed membranes in the gas-solid suspension, on both solid fluxes and bubble properties. They reported that the presence of horizontal membrane tubes decreases the solid fluxes without showing any significant change in the overall circulation patterns in the bed. Moreover, the permeation rate and the membrane tube arrangements barely influence the time averaged solid flux profiles. However, membrane tube arrangements significantly influenced the number of bubbles and the average bubble size; configurations with smaller membrane tubes showed a decrease in the number of bubbles. In a similar study, Teklay A. et al. [28] also confirmed that, in comparison to beds without internal obstacles (submerged horizontal tubes), beds with internal tubes significantly changes the bubble properties. They went further into the 
detailed studies of effects of immersed tubes, and confirmed that the bubble properties were strongly influenced by the geometry of the immersed tubes and found to be nearly independent of superficial velocity, particle size and bed height. Recently, Julian et al. [29] have studied the effect of tube banks in two zones fluidized bed membrane reactors with PIV/DIA, confirming the change of fluidization behaviour due to the bubble breakage caused by the membranes; however, in similar configurations (horizontal membranes), Medrano et al. [30] demonstrated the occurrence of gas pockets surrounding the membranes that could reduce the mass transfer rates to the membranes and thus the membrane efficiency. Deshmukh et al. [31-33] performed both numerical and experimental works on effects of gas permeation via membranes and also found a reduction in both bubble sizes and solids motion. Dang et al. [34] and Tan et al. [35,36] studied the effect of gas permeation through vertical membranes for small scale fluidized bed reactors. Tan et al. [37] also numerically studied the effect of gas permeation on the hydrodynamic characteristics of membrane-assisted micro fluidized beds.

This paper extends the study of de Jong et al. [26] on vertical flat membranes by investigating both experimentally and numerically the effects of the insertion of a number of vertical flat membranes covering larger areas of the bed; specifically, the effect of extraction rate and location was investigated. In the next sections a detailed description of the experimental setup and methods is presented followed by a similar outline of the reactive multiphase flow simulations. Then, the experimental and numerical results of bubble properties, such as bubble size distribution and bubble velocity as a function gas extraction rate and extraction configurations will be discussed and compared. Finally, conclusions of the study will be presented.

\section{Experimental setup and model description}

This experimental study was performed using a fluidized bed setup specifically designed to investigate the effect of gas extraction through vertical membranes on the fluidized bed hydrodynamics. A pseudo-2D fluidized bed column with specific dimensions of $300 \mathrm{~mm}$ width, $1500 \mathrm{~mm}$ height and $15 \mathrm{~mm}$ depth was used. A schematic diagram of the bed is shown in Fig. 2a.

The front wall was made of transparent glass to allow for visual observations of solid and bubble dynamics within the bed, which is a fundamental requirement for the use of digital image analysis. For the back wall, an anodized metal (to obtain a good contrast between the particles and gas phases) was used where a multi-chamber porous plate was constructed and mounted at the bottom of the back plate in order to simulate vertical membrane insertion (Fig. 2b). Gas can be extracted in specific areas on the back of the column, in order to investigate the effect of gas extraction through vertical membranes on bed hydrodynamics.

Porous plates used to simulate membranes were $3 \mathrm{~mm}$ in thickness with a mean pore size of $5 \mu \mathrm{m}$ (the lowest possible porosity to obtain high pressure drop and circumvent possible gas by-pass). Fourteen individual porous plates were arranged in two rows (each $200 \mathrm{~mm}$ in height) and seven columns spanning the width of the bed. These plates were designed in such a way that individual porous plates can be easily controlled (closed or opened); hence different membrane configurations could be conveniently investigated by closing or opening the appropriate easily accessible ports. The distributor at the bottom of the bed was made of porous metal with an average pore size of $20 \mu \mathrm{m}$ and $3 \mathrm{~mm}$ thickness. Glass beads with a particle density of $2500 \mathrm{~kg} / \mathrm{m}^{3}$ (Geldart B classification) and mean particle sizes of $190 \mu \mathrm{m}$ were used as the bed medium. The minimum fluidization velocity for these particles was determined as $0.0704 \mathrm{~m} / \mathrm{s}$ (by standard pressure drop method). All experimental results reported here have been performed with a total gas feed of $5.3 \mathrm{U}_{\mathrm{mf}}$.

Air was used as the fluidizing gas and the flow rate was controlled by digital mass flow controllers (Bronkhorst), with a range up to $500 \mathrm{~L} / \mathrm{min}$. In order to reduce electrostatic forces between the wall and particles that may be generated during fluidization, the air was humidified to $50-70 \%$ relative

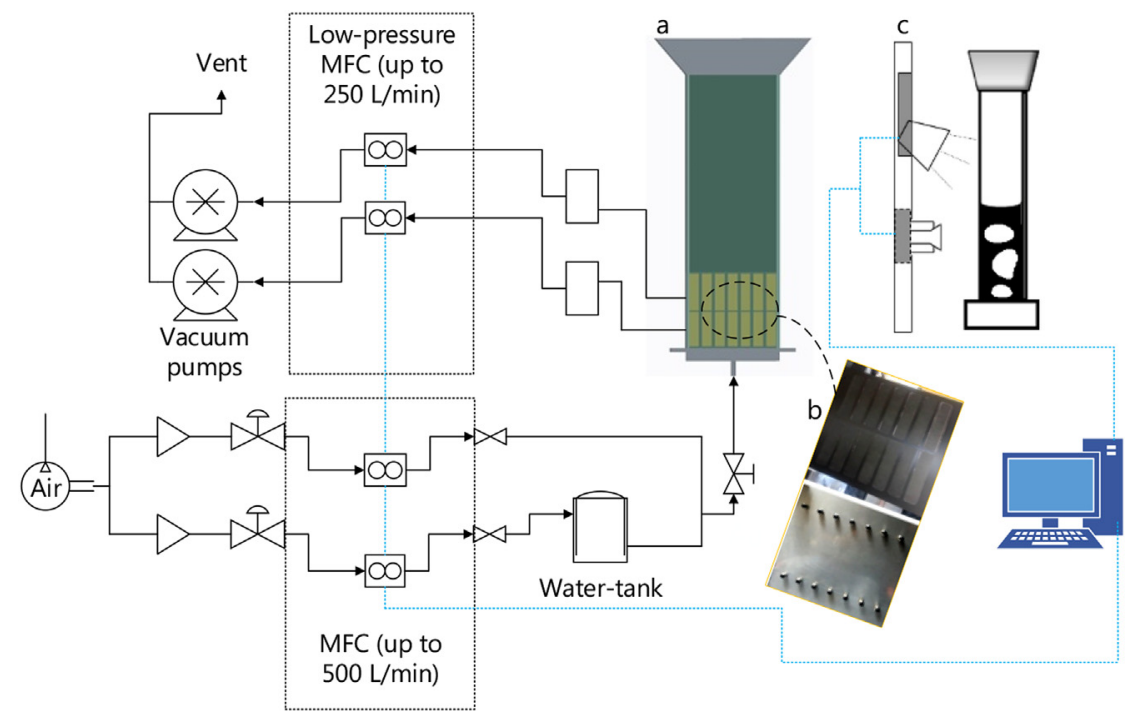

Fig. 2 - a) Process flow diagram of the experimental set up, b) picture of front view (top) and rear view (bottom) of the multi-chamber plate, c) optical scheme. 
humidity by passing the feed through a water tank which was mounted online with the gas feed. The two rows of porous plates representing the membranes (7 each) mounted at the bottom of the back plate were connected to two low-pressure mass flow controllers (Bronkhorst) and in turn connected to two vacuum pumps in parallel for gas extraction.

Images of the flow dynamics were recorded by a commercial high resolution, progressive scan CCD camera (FlowSense EO 11M Camera from Dantec operated with DynamicStudio software), with a maximum resolution of $4032 \times 2688$ pixels and a frame rate of $1.6 \mathrm{~Hz}$, which was placed in front of the bed. For flow dynamics visualization, the fluidized bed was illuminated by an LED lamp which was also placed in front of the bed (placed in proper position to avoid any reflection). In each experiment, more than 1500 images (with time step of $1.5 \mathrm{~ms}$ between two consecutive images) were taken and processed.

\section{Description of experiments}

In this study, two experimental campaigns have been performed. In the first campaign, the effects of variation of gas extraction rates on the bubble properties were investigated. The total gas feed for fluidization was kept constant, while the gas extraction rate through the vertical flat porous plates was altered between $0 \%$ and $40 \%$ of the total feed rate. All fourteen porous plates were used for gas extraction.

Even though the main aim of this research is to investigate the effects of gas extraction via vertical membranes on the hydrodynamics, the selection of gas extraction rates should be related to the actual membrane permeation rates that are practicable in hydrogen perm-selective membrane reactors. As reported in the recent review paper of Gallucci et al. [38], a wide range of membrane fluxes have been presented. The highest membrane fluxes reported [39] resulted in an extraction gas velocity of $0.036 \mathrm{~m} / \mathrm{s}$ (this flux corresponds to a permeance of $1.5 \times 10^{-2} \mathrm{~mol} \mathrm{~m}^{-2} \mathrm{~s}^{-1} \mathrm{pa}^{-0.5}$ ) with hydrogen feed of 26 bar and measured at $400{ }^{\circ} \mathrm{C}$ which is about one order of magnitude higher than the highest extraction rate used in this campaign. If operated at higher temperatures $\left(600^{\circ} \mathrm{C}\right)$ and pressures (retentate side) the flux would increase even further. Accordingly, the selected experimental conditions in this study with gas extraction velocities of $0.0026-0.0053 \mathrm{~m} / \mathrm{s}(20-40 \%)$ are therefore in the same order of magnitude as predicted in the existent hydrogen perm-selective membranes.

In the second experimental campaign, the effects of extraction location (membrane configuration) and the total membrane surface area, on the bubble properties have been studied. For this campaign, an extraction rate of $30 \%$ of the inlet flowrate was selected, while the extraction location and the total number of active membrane plates were varied. The extraction location was varied from the largest area (all 7 membrane columns) to the smallest area (only a single membrane column at the centre). Different extraction locations and typical sample images of each arrangement are shown in Fig. 3. In both experimental campaigns, the static bed height was kept identical to the total membrane height $(40 \mathrm{~cm})$.

\section{Digital image analysis (DIA) technique}

In recent years the use of the DIA technique in fluidization studies has increased substantially for three main reasons: 1) the advancement of digital imaging devices, 2) the nonintrusive nature of the technique, and 3) its ability to provide detailed information about both solid and bubble phase properties. However, the drawback of this method is that it can only be effectively used in pseudo-2D beds.

Lim and Agarwal et al. [40-42] were the first to use DIA technique to perform experimental investigations on bubble properties and solid tracer concentration profiles on a 2D bed. Hull et al. $[43,44]$ also used DIA to study bubble properties and tracer concentrations on beds with/without internals. Laverman et al. [45] used coupled PIV/DIA techniques to determine the time-averaged emulsion phase velocity profiles from the obtained instantaneous particle velocity profiles (PIV) and correct for the influence of particle raining through the roof of the bubbles. They studied the solid phase circulation pattern and bubble properties. Shen et al. [46] also employed DIA with a digital video camera and studied simultaneously the size and velocity of gas bubbles, and the axial and radial distribution of bubble voidage. In mono-dispersed and binary mixtures, Goldschmidt et al. [47] used DIA techniques to measure bed expansion and segregation dynamics in dense gas-fluidized beds. Busciglio et al. [48] also studied bubble hold up and bed expansion in bubbling fluidized bed of binary mixtures of particles using the DIA technique. Caicedo et al. [49] used the DIA technique to measure bubble aspect ratio and shape factor in a 2D gas-solid fluidized bed. For further details about DIA technique the interested reader can refer to de Jong et al. [26].

In this study, more than 1500 double frame images were recorded with a high resolution CCD camera for each DIA experiment. This was found to be sufficient for the statistical analysis of bubble properties. As a matter of fact, the average relative error of two independent time-averaged images (1200 and 1550) as a function of the number of bubbles found in the whole bed was less than $5 \%$. This is in line with findings from de Jong et al. [26] who found that for 1350 images the deviation ranges from $1 \%$ in the bottom of the bed to $4 \%$ in the top. For the results discussed in this study, the time step between two consecutive images recorded with the high resolution camera was set to $1.5 \mathrm{~ms}$.

After the images were taken, post processing was carried out with an in-house code developed using Matlab image processing toolbox. Each recorded image was passed through number of processing steps: correction of inhomogeneous illumination and background disturbances, image smoothing and filtering, bubble detection based on a pre-set threshold value (a threshold value of 0.25 was used to discriminate the bubble phase from the emulsion), bubble labelling and finally measuring sizes and locations. In addition, bubbles that are too small, bubbles with poor illumination near the walls and bubbles that are connecting to the freeboard were removed in the post-processing. The code was calibrated and validated using circular shapes of black tape (considered as bubble) placed on the bed with predefined sizes and locations. A typical DIA result is shown in Fig. 4. 
a)

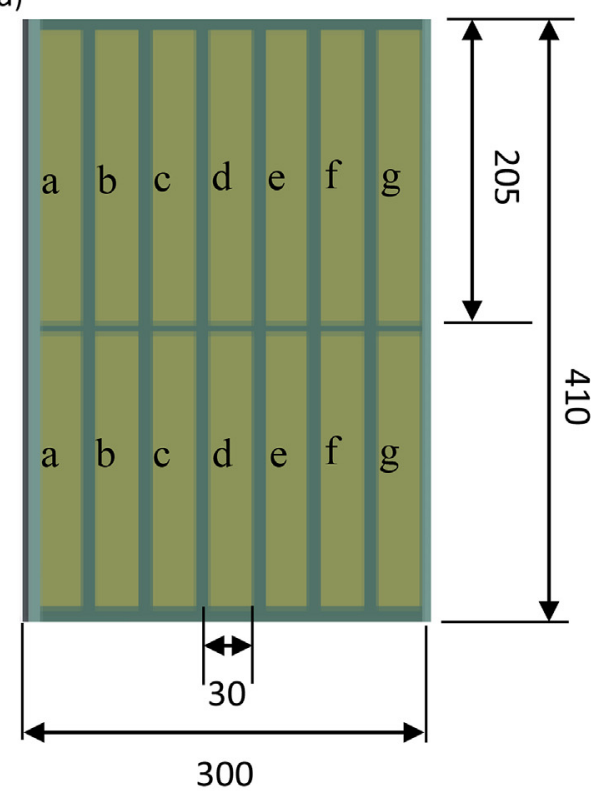

c)

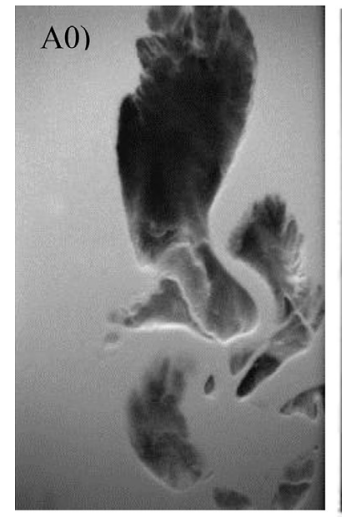

b) 1
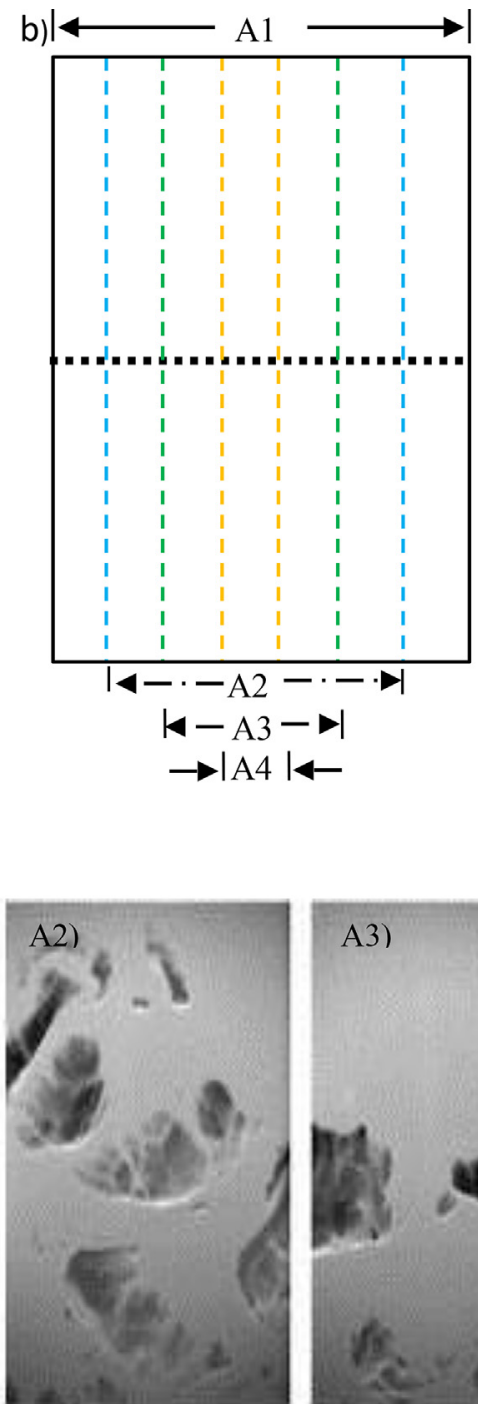
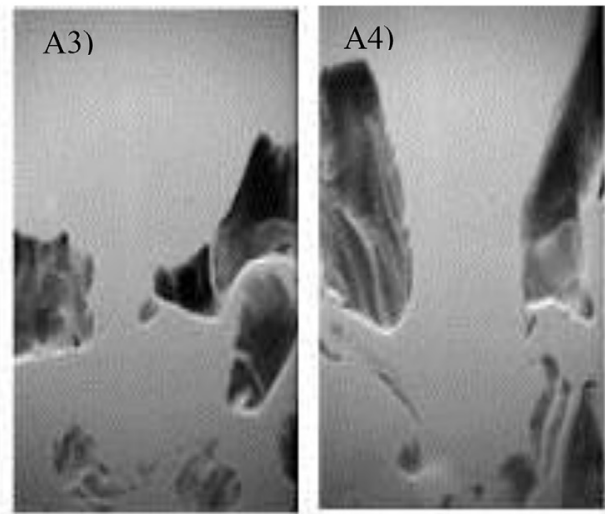

Fig. 3 - a) Front view of the multi-chamber (all dimensions in $\mathrm{mm}$ ), b) The area coverage of active membranes (decreasing towards the centre); c) sample images for gas extraction: A0) no extraction, A1) through all (a-b-c-d-e-f-g), A2) through 5 membranes (b-c-d-e-f), A3) through 3 membranes (c-d-e), and A4) through 1 membrane (d).

Three main bubble properties were recorded: an equivalent bubble diameter, horizontal and vertical coordinates (Centroids) of the bubble using its centre of gravity and the bubble rise velocity.

The equivalent bubble diameter was determined using its projected surface area as:

$\mathrm{d}_{\mathrm{B}}=\sqrt{4 \mathrm{~A}_{\mathrm{B}} / \pi} \mathrm{d}_{\mathrm{B}}=\sqrt{\frac{4 \mathrm{~A}_{\mathrm{B}}}{\pi}}$

whereas, the rise velocity was determined by taking the change in the vertical coordinates of centroids between the consecutive image-frames divided by the time step between the frames.

$\mathrm{d}_{\mathrm{B}}=\sqrt{4 \mathrm{~A}_{\mathrm{B}} / \pi} \mathrm{V}_{\mathrm{B}}=\frac{\left[\mathrm{C}_{\mathrm{y}}(\mathrm{t}+\Delta \mathrm{t})-\mathrm{C}_{\mathrm{y}}(\mathrm{t})\right]}{\Delta \mathrm{t}}$

where, $C_{y} C_{y}$ is the vertical component of centroids of the bubble, $\mathrm{t}$ is the time and $\Delta \mathrm{t}$ is the time step between consecutive images, $A_{B} A_{B}$ is projected surface area.

\section{Simulations}

Fully 3D simulations were completed of the pseudo-2D geometry using the standard Two Fluid Model (TFM) approach. This section will only give a brief outline of model setup, but a more complete version can be found in an earlier work by Cloete S. et al. [50].

Both hydrodynamic and reactive simulations were completed. Hydrodynamic simulations were primarily completed for the purpose of comparing to experiments, while the main purpose of reactive simulations was to assess the degree to which hydrodynamic simulations/experiments approximate the real reactive situation. Aside from the obvious material property differences, there are two main differences between the hydrodynamic and reactive cases: 1 ) while hydrodynamic cases have a fixed extraction rate through all active membranes, extraction in the reactive case is proportional to the local hydrogen concentration, and 2) additional gas is formed via a shift in the reaction equilibria 
when hydrogen is extracted in the reactive case. These differences are expected to lead to some differences in the behaviour of the reactive case relative to the hydrodynamic case.

\section{Model equations}

Mass was conserved for each phase (q) as follows:

$\frac{\partial}{\partial t}\left(\alpha_{q} \rho_{q}\right)+\nabla \cdot\left(\alpha_{q} \rho_{q} \vec{v}_{q}\right)=0$

Momentum conservation was calculated as follows for the gas and solid phases, respectively:

$$
\begin{aligned}
\frac{\partial}{\partial t}\left(\alpha_{g} \rho_{g} \vec{v}_{g}\right)+\nabla \cdot\left(\alpha_{g} \rho_{g} \vec{v}_{g} \vec{v}_{g}\right)= & -\alpha_{g} \nabla p+\nabla \cdot \overline{\bar{\tau}}_{g}+\alpha_{g} \rho_{g} \vec{g} \\
& +K_{\mathrm{sg}}\left(\vec{v}_{s}-\vec{v}_{g}\right)
\end{aligned}
$$

$$
\begin{aligned}
\frac{\partial}{\partial t}\left(\alpha_{s} \rho_{s} \vec{v}_{s}\right)+\nabla \cdot\left(\alpha_{s} \rho_{s} \vec{v}_{s} \vec{v}_{s}\right)= & -\alpha_{s} \nabla p-\nabla p_{s}+\nabla \cdot \overline{\bar{\tau}}_{s}+\alpha_{s} \rho_{s} \vec{g} \\
& +K_{g s}\left(\vec{v}_{g}-\vec{v}_{s}\right)
\end{aligned}
$$

The inter-phase momentum exchange coefficient $\left(K_{\mathrm{gs}}=K_{\mathrm{sg}}\right)$ was modelled according to the Syamlal and O'Brian drag model [51].

Solids stresses were modelled according to the Kinetic Theory of Granular Flows (KTGF) using the concept of granular temperature. The standard granular temperature conservation equation is written as follows:

$$
\begin{aligned}
\frac{3}{2}\left[\frac{\partial}{\partial t}\left(\alpha_{s} \rho_{s} \Theta_{s}\right)+\nabla \cdot\left(\alpha_{s} \rho_{s} \vec{v}_{s} \Theta_{s}\right)\right]= & \left(-p_{s} \overline{\bar{I}}+\overline{\bar{\tau}}_{s}\right): \nabla \vec{v}_{s}+ \\
& \nabla \cdot\left(k_{\Theta_{s}} \nabla \Theta_{s}\right)-\gamma_{\Theta_{s}}+\phi_{g s}
\end{aligned}
$$

This partial differential equation was simplified to an algebraic equation by neglecting the convection and diffusion terms - an assumption which is often used in dense fluidized beds where the local generation and dissipation of granular temperature far outweighs the transport by convection and diffusion [51]. The two final terms on the right hand side are the collisional dissipation of energy [52] and the interphase exchange between the particle fluctuations and the gas phase [53].

Solids stresses are calculated according to shear (collisional [51,54] kinetic [51] and frictional [55]) and bulk [53] viscosities. For the solids pressure, the formulation of Lun et al. [53] was complemented by the radial distribution function of Ogawa and Oshima [56]. The frictional pressure formulation of Johnson [57] was also included to accurately represent dense flow regions.

This concludes the model setup for the hydrodynamic simulations completed in this study. The reactive simulations completed also included species transport and reactions as outlined below:

Since only catalytic reactions were simulated, species are conserved only for the gas phase. No turbulence effects on species diffusion were simulated as this effect was found to be small even under fast fluidization and high reaction rates [58]. The current case features slower fluidization and reaction rates, implying that turbulent species diffusion will be negligible.

$\frac{\partial}{\partial t}\left(\alpha_{g} \rho_{g} Y_{g, i}\right)+\nabla \cdot\left(\alpha_{g} \rho_{g} \vec{v}_{g} Y_{g, i}\right)=\nabla \cdot \alpha_{g} \vec{J}_{g, i}+\alpha_{g} S_{g, i}$

No energy equation was solved in this work. For the reactive simulations, only catalytic reactions were simulated under isothermal flow at $600{ }^{\circ} \mathrm{C}$. This assumes a heat supply which exactly balances out the endothermic reactions.

The following combination of catalytic reactions are included in this study:

$$
\begin{aligned}
& \mathrm{CH}_{4}+\mathrm{H}_{2} \mathrm{O} \leftrightarrow \mathrm{CO}+3 \mathrm{H}_{2} \\
& \mathrm{CO}+\mathrm{H}_{2} \mathrm{O} \leftrightarrow \mathrm{CO}_{2}+\mathrm{H}_{2} \\
& \mathrm{CH}_{4}+2 \mathrm{H}_{2} \mathrm{O} \leftrightarrow \mathrm{CO}_{2}+4 \mathrm{H}_{2}
\end{aligned}
$$

The rates of these reactions are calculated from the set of equations first proposed by Xu \& Froment [59]:
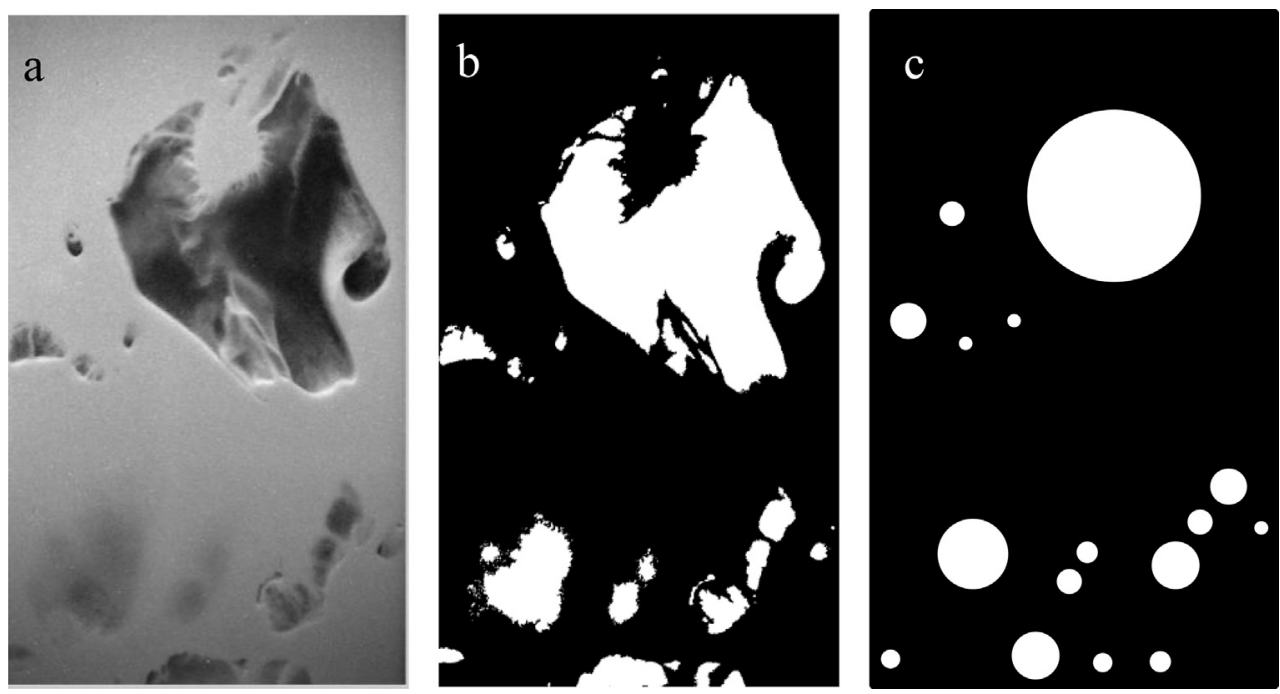

Fig. 4 - (a) Original image (b) Processed image (c) Equivalent bubble surface area. 
$r_{1}=\frac{k_{1}}{p_{\mathrm{H}_{2}}^{2.5}}\left(p_{\mathrm{CH}_{4}} p_{\mathrm{H}_{2} \mathrm{O}}-\frac{p_{\mathrm{H}_{2}}^{3} p_{\mathrm{CO}}}{\mathrm{K}_{1}}\right) /(\mathrm{DEN})^{2}$

$r_{2}=\frac{k_{2}}{p_{\mathrm{H}_{2}}}\left(p_{\mathrm{CO}} p_{\mathrm{H}_{2} \mathrm{O}}-\frac{p_{\mathrm{H}_{2}} p_{\mathrm{CO}_{2}}}{K_{2}}\right) /(\mathrm{DEN})^{2}$

$r_{3}=\frac{k_{3}}{p_{\mathrm{H}_{2}}^{3.5}}\left(p_{\mathrm{CH}_{4}} p_{\mathrm{H}_{2} \mathrm{O}}^{2}-\frac{p_{\mathrm{H}_{2}}^{4} p_{\mathrm{CO}_{2}}}{K_{3}}\right) /(\mathrm{DEN})^{2}$

$D E N=1+K_{\mathrm{CO}} p_{\mathrm{CO}}+K_{\mathrm{H}_{2}} p_{\mathrm{H}_{2}}+K_{\mathrm{CH}_{4}} p_{\mathrm{CH}_{4}}+K_{\mathrm{H}_{2} \mathrm{O}} p_{\mathrm{H}_{2} \mathrm{O}} / p_{\mathrm{H}_{2}}$

The values of the adsorption coefficients used in this study are obtained from Oliveira [60]. Table 1 summarizes the kinetic [60] and equilibrium [61] parameters used in this study.

Geometry, mesh, boundary conditions, materials and solver The experimental geometry was duplicated in the 3D simulations and meshed with $2.5 \mathrm{~mm}$ cubical cells. Gas was fed through a velocity inlet at the bottom face of the geometry and exited through a pressure outlet at the top. The hydrodynamic cases used a gas inlet velocity of $0.373 \mathrm{~m} / \mathrm{s}$ similar to that used in the experiments. Reactive runs were completed with an inlet velocity of $0.3 \mathrm{~m} / \mathrm{s}$ and a steam/methane feed ratio of 2:1. This flowrate was found to result in similar fluidization than that observed in the hydrodynamic simulations. The particle phase properties were kept identical to the experimental case in all simulations.

No-slip wall boundary conditions were specified for the gas, while the partial slip conditions of Johnsen \& Jackson [57] with a specularity coefficient of 0.5 was applied for the solids. In addition, it was found that an additional wall friction proportional to the frictional pressure with a friction coefficient of 0.1 was required to capture stagnant zones forming when gas is extracted via membranes. Thus, the following shear stress was implemented at the walls:

$\vec{\tau}_{s}=-0.5 \frac{\pi}{6} \sqrt{3} \frac{\alpha_{s}}{\alpha_{s, \max }} \rho_{s} g_{0, s s} \sqrt{\Theta_{s}} \vec{U}_{s, \|}-0.1 p_{s, f r i c} \frac{\vec{U}_{s, \|}}{\left|\vec{U}_{s, \|}\right|}$

Gas extraction through membranes was simulated via a sink term in the layer of cells closest to the back wall. For the hydrodynamic simulations, this was implemented as a constant in the appropriate cells, while the following formulation was used to describe the membrane permeability in the reactive case [62]:

$J_{\mathrm{H}_{2}}=C \frac{P_{\text {mem }}}{t_{\text {mem }}}\left(p_{\mathrm{H}_{2} \text {,fluid }}^{n}-p_{\mathrm{H}_{2}, \text { perm }}^{n}\right)$

$P_{m e m}=e^{a_{1} T^{2}+a_{2} T+a_{3}}$

$n=b_{1} T^{2}+b_{2} T+b_{3}$

The constant values used are $a_{1}=5.183 \times 10^{-5}$, $a_{2}=-6.474 \times 10^{-2}, \quad a_{3}=-7.235, \quad b_{1}=-3.910 \times 10^{-6}$, $b_{2}=4.964 \times 10^{-3}$ and $b_{3}=-0.5697$. A membrane thickness, $t_{\text {mem }}$, of $4.5 \times 10^{-6} \mathrm{~m}$ was used.

The constant $C$ in Eq. (13) was adjusted from case to case in order to achieve the desired amount of overall gas extraction.
Firstly, the case with no gas extraction was simulated and the volume flowrate of gas exiting the reactor was monitored. Subsequently, the membranes were activated and the constant $C$ was adjusted so that the outlet flowrate becomes the desired percentage smaller than the case with no extraction. This methodology most closely approximated the hydrodynamic simulations and facilitated a direct comparison. Gas phase material properties were calculated according to the species composition in each particular cell. The ideal gas law was used for density, while kinetic theory was used to calculate viscosity and molecular diffusivity. Solids phase properties were identical to experiments: $2500 \mathrm{~kg} / \mathrm{m}^{3}$ density and $190 \mu \mathrm{m}$ particle size.

Simulations were carried out using ANSYS FLUENT 15.0. The phase coupled SIMPLE scheme [63] was used for pressure-velocity coupling. Spatial discretization of the remaining equations was performed using the higher order QUICK scheme [64]. 1st order implicit temporal discretization was used.

\section{Results and discussions}

Results will be presented and discussed in two main sections: 1) a detailed account of the experimental observations where the effect of gas extraction through vertical plates on bed hydrodynamics is thoroughly investigated and 2) a simulation study where hydrodynamic simulation results are compared to experiments to assess model accuracy and to reactive simulations to assess the reliability of using cold flow studies to approximate real reactor performance.

\section{Experimental hydrodynamics}

Bubble size and rise velocity are the two hydrodynamic parameters with the greatest influence on the reactor performance of bubbling fluidized beds. We will therefore focus on discussing the effect of gas extraction rate and location on the bubble properties in terms of bubble size distribution in both axial and radial positions and bubble rise velocity as a function of equivalent bubble diameter.

Average bubble diameter and number of bubbles per frame Normally due to bubble coalescence, bubble size increases with bed height and superficial velocity provided that there is no intrusion in the flow dynamics of the fluidized beds. Small bubbles are formed at the distributor and grow due to coalescence as they rise towards the freeboard. Figs. 5 and 6 show the average bubble diameter as a function of the height of the bed. Fig. 5 also includes bubble size correlations proposed by Shen et al. [46] (Eq. (16)) and Lim et al. [42] (Eq. (17)).

$$
\begin{aligned}
& d_{B}=\sqrt{4 A_{B} / \pi} d_{B}=0.89\left[\left(u_{0}-u_{m f}\right)\left(h+\frac{3 A_{0}}{t_{b}}\right)\right]^{2 / 3} g^{-1 / 3} \\
& d_{B}=\sqrt{4 A_{B} / \pi} d_{B}=\left[\frac{5.456\left(u_{0}-u_{m f}\right)}{\pi \lambda \sqrt{g}} h+d_{0}^{3 / 2}\right]^{2 / 3}
\end{aligned}
$$

Here $h$ is the height, $A_{0} A_{0}$ is the catchment area, $t_{b}$ is the 
Table 1 - Summary of reaction rate $(k)$ and equilibrium $(K)$ parameters (applied in a standard Arrhenius equation) for the reforming reactions simulated in this study.

\begin{tabular}{|c|c|c|c|c|}
\hline \multirow[t]{2}{*}{ Reaction } & \multicolumn{2}{|c|}{ Kinetic parameters } & \multicolumn{2}{|c|}{ Equilibrium parameters } \\
\hline & $k_{j, 0}$ & $\overline{E_{a}(\mathrm{~kJ} / \mathrm{mol})}$ & $K_{0}$ & $\overline{E_{a}(\mathrm{~kJ} / \mathrm{mol})}$ \\
\hline Methane reforming & $5.83 \times 10^{11}\left(\mathrm{~mol} \mathrm{bar}^{0.5} /(\mathrm{kg} \mathrm{s})\right)$ & 218.55 & $1.2 \times 10^{13}$ & 223.08 \\
\hline Water gas shift & $2.51 \times 10^{4}(\mathrm{~mol} /(\mathrm{kg} \mathrm{s}$ bar $))$ & 73.523 & $1.77 \times 10^{-2}$ & -36.58 \\
\hline Overall methane reforming & $4.67 \times 10^{13}\left(\mathrm{~mol} \mathrm{bar}^{0.5} /(\mathrm{kg} \mathrm{s})\right)$ & 236.85 & $2.124 \times 10^{11}$ & 186.5 \\
\hline
\end{tabular}

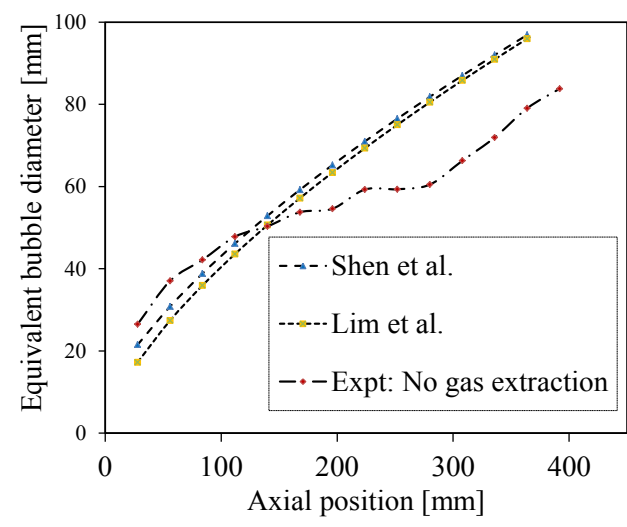

Fig. 5 - Comparison of average bubble diameter as a function of the bed height between experiment (no extraction) and literature correlations.

depth of the bed, $\lambda$ is the proportionality constant (estimated as 2) and $d_{0} d_{0}$ is the initial bubble diameter which is given by:

$\mathrm{d}_{\mathrm{B}}=\sqrt{4 \mathrm{~A}_{\mathrm{B}} / \pi} \mathrm{d}_{0}=\left[\frac{8\left(\mathrm{u}_{0}-u_{m f}\right) \mathrm{A}_{0}}{\pi \lambda \sqrt{g}}\right]^{2 / 3}$

Both models predicted fairly similar bubble growth along the bed height and agree reasonably well with the experiments. The over prediction of the bubble diameter in the lower part of the fluidized bed by the experimental work can be attributed to the fact that smaller bubbles were not considered in the averaging of equivalent bubble diameter. The deviation from the proposed correlations in the $100-300 \mathrm{~mm}$ (distance between the upper part of the bottom membranes and the connector of the two chambers) interval of the bed height might be due to some amount of gas being short circuited through the chamber behind the plate influence the bubble growth.

As could be expected, Fig. 6 shows that the horizontally averaged bubble diameter increases and number of bubbles decreases along the axial position of the bed. The influence of gas extraction rate (Fig. 6 a) is remarkably small, implying that the effect of extraction rate on axial bubble dynamics must be reflected more strongly in the bubble rise velocity (discussed in the next section and around Fig. $8 \mathrm{~b}$ in this section).

The variation of gas extraction locations, on the other hand, had a significant effect on the axial bubble size and number particularly at higher bed heights (Fig. $6 \mathrm{~b}$ ). The most noticeable aspect is the fact that extraction at the centre of the bed (with one and three membranes) resulted in smaller bubble size (especially starting from a height of $0.3 \mathrm{~m}$ ) while having higher number of bubbles. As will be discussed in greater detail around Fig. 9, this is due to the bubble stream effectively being split into two parts rising on the left and right of the bed. This phenomenon limits bubble coalescence, thereby resulting in a larger number of smaller bubbles.

Comparisons of bubble size and number of bubbles for the two cases (effects of gas extraction rates and location) as a function of lateral position are shown in Figs. 7 and 9 In the case of variation of gas extraction rates (Fig. 7), vertically averaged bubble sizes and number of bubbles per frame show similar distributions with bubbles residing more towards to the centre. This distribution similarity is because bubble sizes as a function of lateral position are averaged over the entire a)

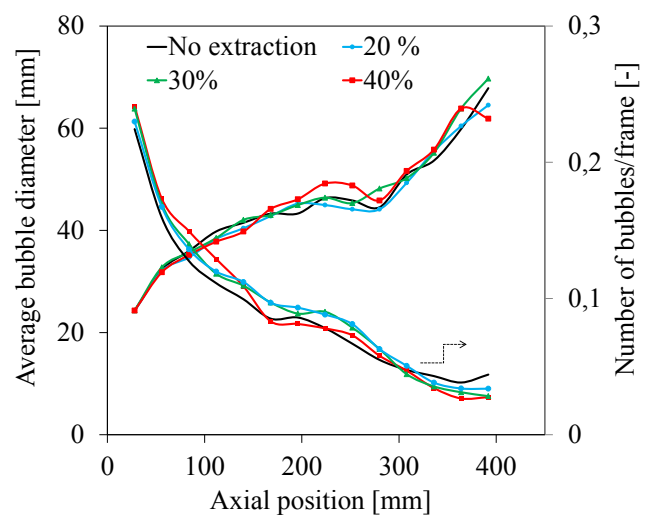

b)

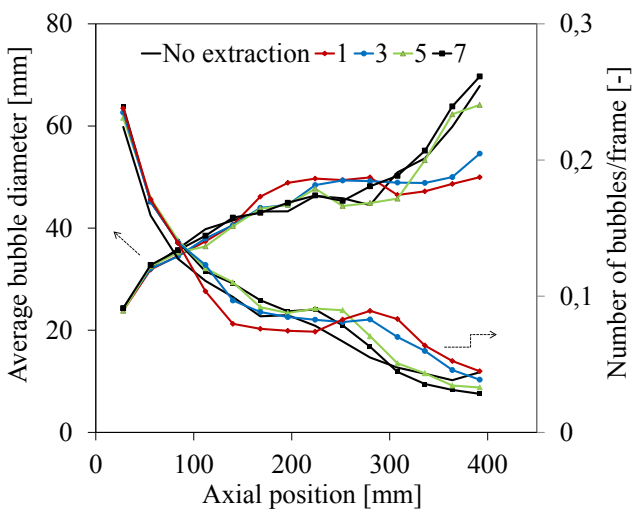

Fig. 6 - Equivalent bubble diameter and number of bubbles per frame as a function of axial position a) for different gas extraction rates and $b$ ) for different gas extraction locations (number of membranes). 


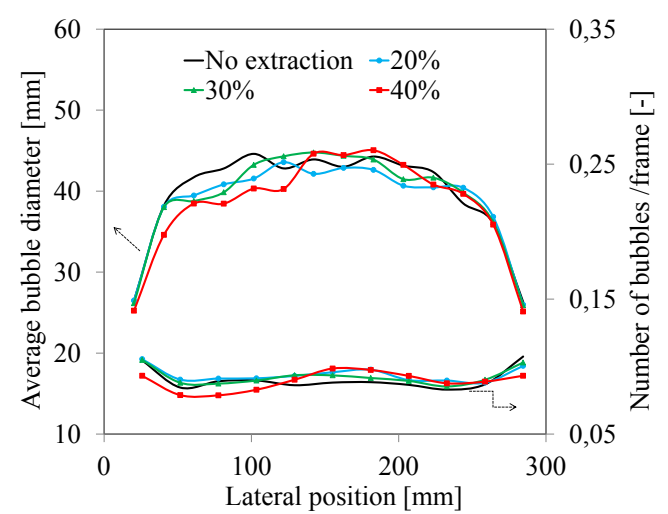

Fig. 7 - Average bubble diameter and number of bubbles per frame as a function of lateral position for different gas extraction rates with respect to the inlet gas flow rate.

bed height; however, the local lateral distribution provides more detailed insight into the bubble behaviour (Fig. 8a and b).

At a lower bed height $(5 \mathrm{~cm}$ from the distributor as shown in Fig. 8a) the lateral bubble profiles for all the cases are indeed very similar, with smaller bubble sizes and higher numbers of bubbles per frame. This is due to the fact that only a small fraction of gas has been extracted at this height and the bubbles have only had a small amount of time to respond to this small amount of gas extraction. On the other hand, at a higher bed height $(33 \mathrm{~cm}$ from the distributor as shown in Fig. $8 b)$ the lateral bubble profile reveals significant differences. In case of no gas extraction, the lateral profile shows the expected parabolic distribution for both bubble size and number of bubbles as bubbles are formed over the whole bed width and move towards the centre due to bubble coalescence. However, as the extraction rate increases a clear trend of increasing gas channelling in the centre of the bed is observed.

Observations of the flow in the fluidized bed revealed that this phenomenon is due to the development of densified zones at the left and right walls when the extraction rate is increased. Since the extraction rate is constant along the entire back plate of the bed, the same amount of gas is

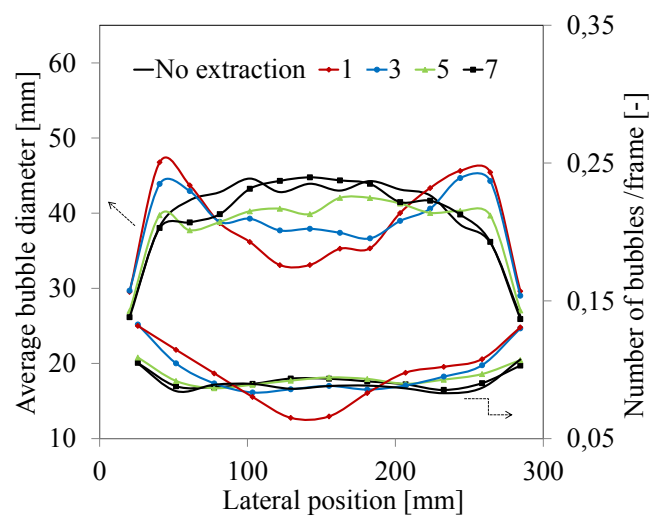

Fig. 9 - Average bubble diameter and number of bubbles per frame as a function of lateral position for different gas extraction configuration with $30 \%$ gas extraction rate.

extracted at the centre (where a large amount of gas rises) and at the walls (where little or no gas rises). This gas extraction is small relative to the large gas flux in the centre of the bed, but large relative to the small gas flux at the sides. As a result, higher extraction rates can lead to the formation of dead zones at the sides of the bed as the suction force from the back causes particles in regions of low/no upwards gas flux to adhere to the back plate. This effect causes gas channelling at the centre of the bed which will be detrimental to the gas-solid contact achieved in a reactor.

Densified zone formation also explains the similarity between cases in Fig. 6a. If all cases were carried out under normal fluidization conditions, the bubble size should decrease substantially along the height of the bed in the cases with gas extraction as the effective fluidization velocity decreases (e.g. Eq. (16)). However, densified zone formation at the sides of the domain effectively narrowed the cross sectional area towards the top of the bed, keeping the effective fluidization velocity roughly the same between different cases.

Fig. 6a shows that, above a bed height of $300 \mathrm{~mm}$, the number of bubbles start decreasing significantly in cases with a)

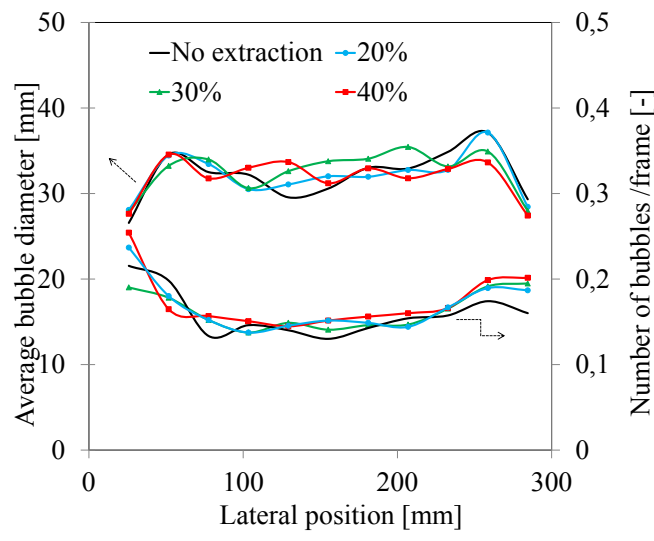

b)

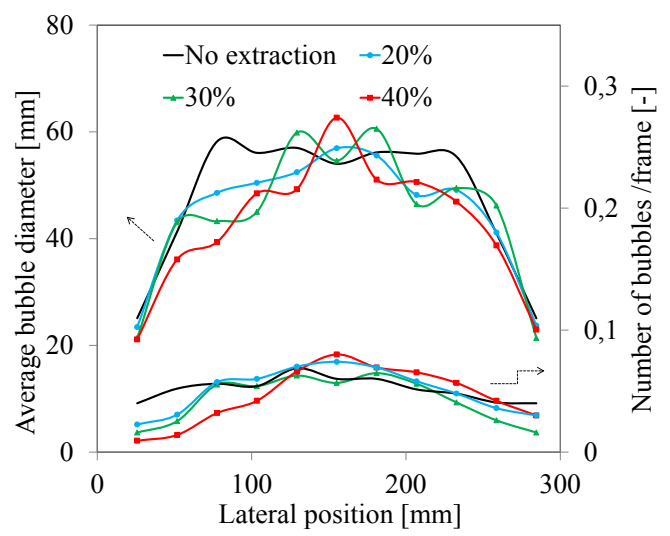

Fig. 8 - Average bubble diameter and number of bubbles per frame as a function of lateral position for different gas extraction rates at two different axial positions: a) at $5 \mathrm{~cm}$ from the distributor, b) at $33 \mathrm{~cm}$ from the distributor. 
a)

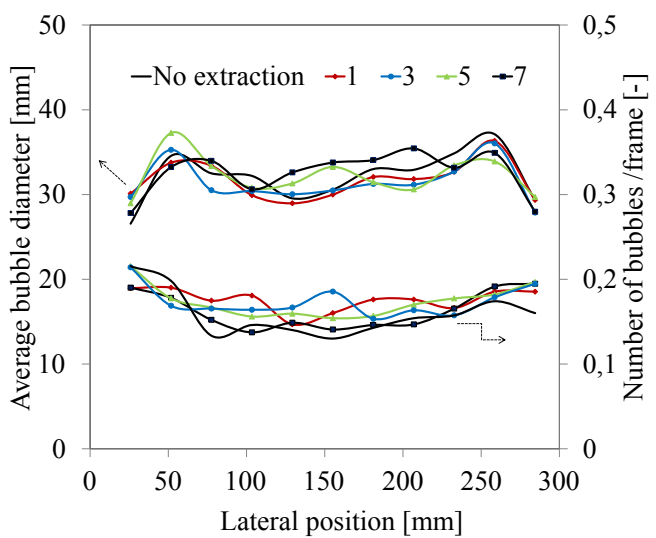

b)

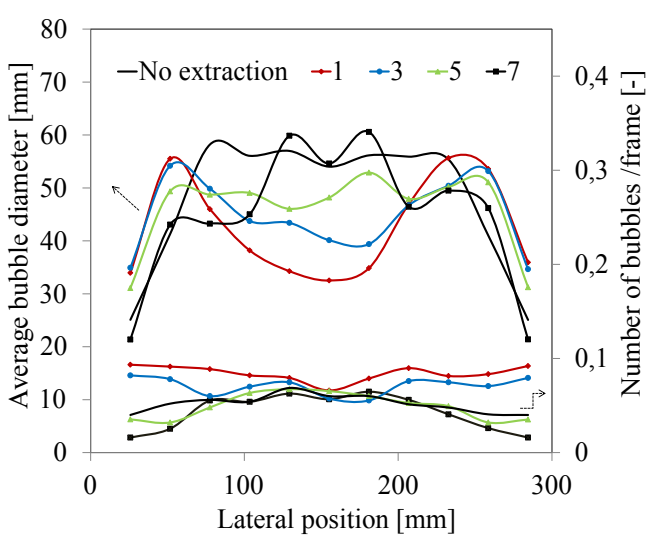

Fig. 10 - Average bubble diameter and number of bubbles per frame as a function of lateral position for different gas extraction location at two different axial positions with $30 \%$ gas extraction rate: a) at $5 \mathrm{~cm}$ from the distributor, b) at $33 \mathrm{~cm}$ from the distributor.

gas extraction relative to the case with no gas extraction. The decreased gas flow rate is thus reflected in a decrease in bubble number rather than a decrease in bubble size. Below $300 \mathrm{~mm}$, however, Fig. 6 a shows that the effective bubble volume (product of bubble size and number) is very similar between the different cases and may even be slightly higher in cases with extraction. This is due to a degree of stagnation of the rising bubbles below the densified zones forming in the upper part of the bed as illustrated in the next section on bubble rise velocity.

Similar to the axial distributions discussed earlier, the effect of gas extraction location was significantly more prominent than the effect of extraction rate. Fig. 9 shows the significant differences even when data is averaged across the entire bed height. As discussed earlier, it is clear from Fig. 9 that the flow splits into two separate bubble streams rising on sides of the bed when extracting gas at the centre through 3 or 1 membrane. This effect is due to the formation of densified zones in the centre where a high gas extraction rate is imposed. When the entire gas extraction rate is imposed at the centre of the bed through 1 or 3 membranes, the local rate of extraction becomes large enough to create densified zones in the centre of the bed through the same mechanism as described previously. The sample images which are shown in Fig. 3 illustrate this phenomenon as well.

Extraction through only 5 membranes still shows the standard flow pattern where gas predominantly rises through the centre. However, bubbles are smaller and more homogenously distributed in the bed relative to the case with extraction throughout the entire bed width. In reactive systems, a higher number of bubbles, small bubble sizes and uniformly distributed bubbles are preferred, in order to decrease the mass transfer limitation of bubble (gas) to emulsion phase. Hence, according to this study, the case with five membranes appears to be the most promising arrangement.

The lateral bubble size and number distribution at the local level for different gas extraction configurations are shown in Fig. 10. Once again, data at a lower height $(5 \mathrm{~cm}$ from the distributor) show little variation between cases, while trends a)

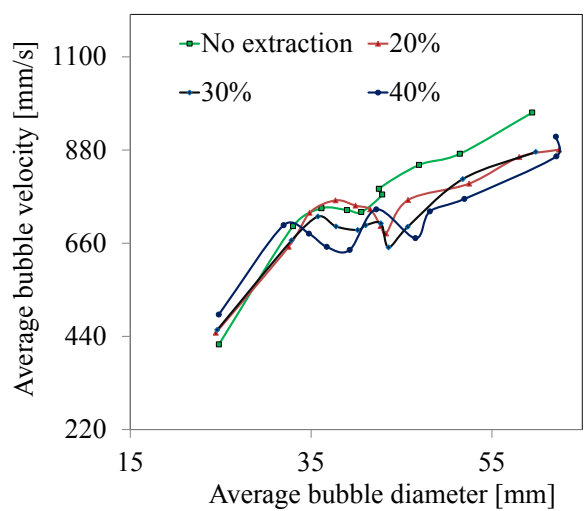

b)

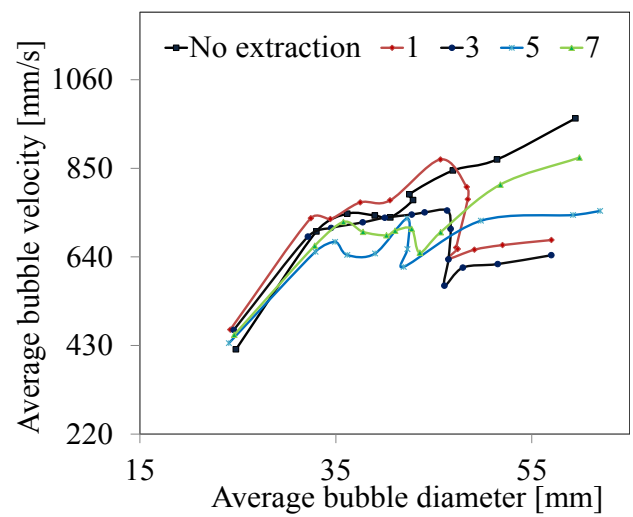

Fig. 11 - Average bubble rise velocity as a function of equivalent bubble diameter: a) for different extraction rates b) for different extraction locations with $30 \%$ gas extraction rate. 


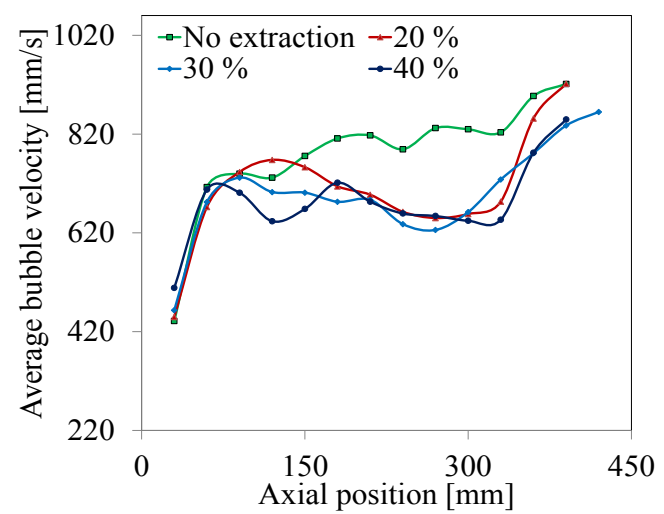

Fig. 12 - Average bubble rise velocity as a function of axial positions for different gas extraction rates.

higher up in the bed (33 $\mathrm{cm}$ from the distributor) show large effects of the extraction location. This reinforces the prior conclusion that the hydrodynamic effects of vertical membrane extraction become much more pronounced in the upper regions of the bed.

Bubble rise velocity

As explained in the experimental section, bubble rise velocity was calculated from the vertical displacement of the bubble centroid between consecutive images. Fig. 11 illustrates the comparisons of average bubble rise velocity as a function of equivalent bubble diameter for different gas extraction rates and location. As expected, the bubble rise velocity increases with the equivalent bubble diameter.

Fig. 11a shows that gas extraction causes a significant reduction in bubble rise velocity, especially for larger bubbles. Even though this effect of extraction rate of bubble rise velocity is relatively small, it is more evident than the effect of extraction rate on bubble size and number (Fig. 6). In addition, Fig. 12 depicts the average bubble rise velocity as a function of the axial position of the bed. There is a significant difference in the rise velocity of the bubbles; particularly, the bubble rise velocity in case without extraction increases along the axial position, while the rise velocity when considering gas extraction shows a clear decrease in the middle regions of the bed (100-300 mm). This might be due to densified zone formation in the upper part of the bed, where large areas of the active membranes are located. Whereas, as expected the bubble rise velocity, in all the cases shows similar behaviour above a bed height of $300 \mathrm{~mm}$, which increases along the bed height.

In the case of variation of extraction locations (Fig. 11b), similar to bubble size, rise velocity was strongly influenced by the position of extraction. The trends for the cases with gas extraction through 1 and 3 membranes once again differ substantially from the other cases. In this case, the sharp reduction in bubble rise velocity at bubble sizes between 45 and $50 \mathrm{~mm}$ is caused by the splitting of the bubble streams by densified zone formation as described earlier.

\section{Simulations}

Details on the bubble size and number were collected from simulation studies carried out both for cold flow and reactive cases. Simulated bed images were collected as black and white solids volume fraction contour plots on three surfaces located on the back wall, the centre of the bed and the front wall. The contour on the front wall was set to $75 \%$ transparency and the contour in the middle to $50 \%$ transparency in order to capture any 3D effects. Fig. 13 shows the result of this procedure and how it compares to the experimental case. Bubble velocity was not collected due to practical challenges with collecting the images in pairs with a very short time delay as required by the bubble velocity algorithm. The processed data on bubble size and number will be presented as lateral profiles averaged over the top half of the bed since it was clearly shown in Figs. 8 and 10 that the impact of gas extraction is most pronounced in this region.

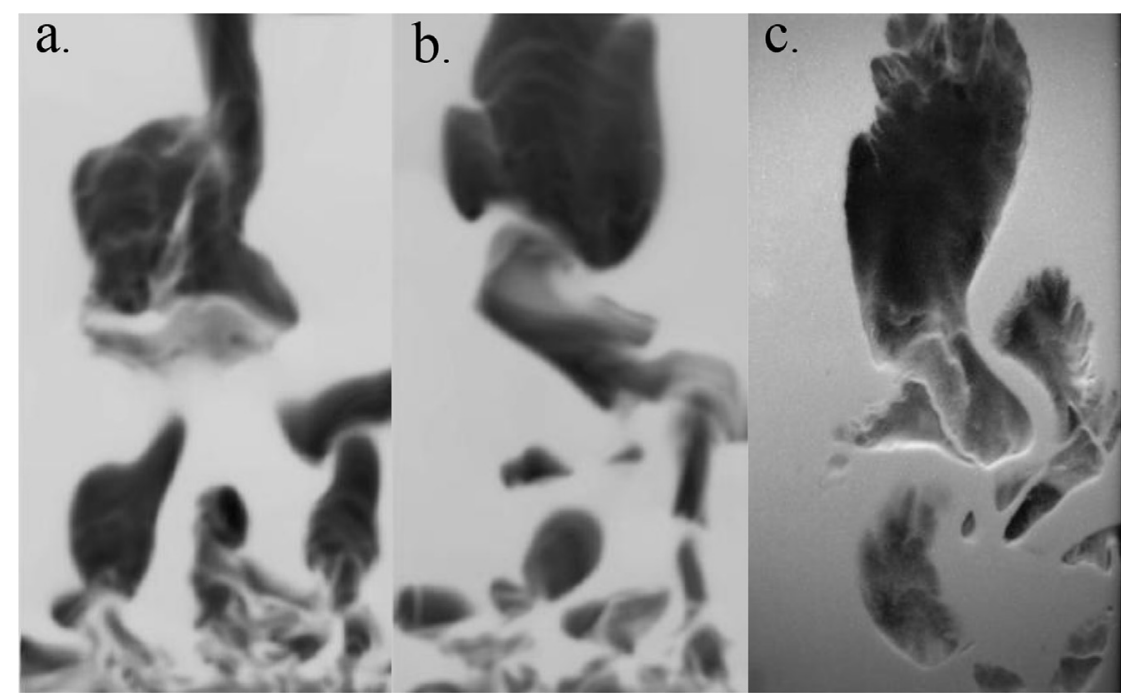

Fig. 13 - Example of a simulated image of the bed compared to the experimental image (no-gas extraction): a) reactive, b) cold flow and c) experimental. 


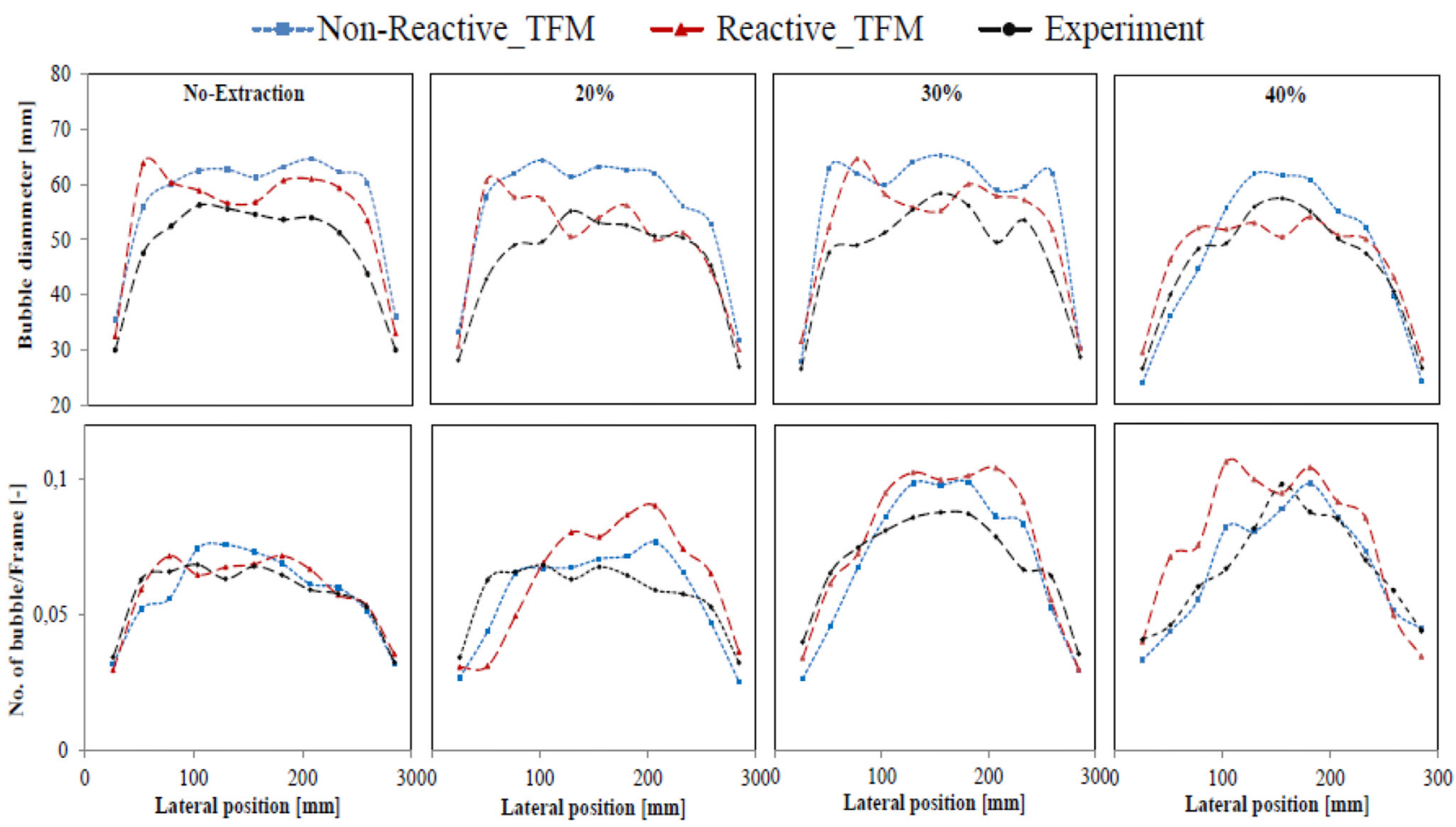

Fig. 14 - Comparison between lateral profiles of bubble size (top) and bubble number (bottom) for the experiments, the coldflow simulations and the reactive simulations for different extraction rates. The lateral profile was averaged over the top half of the membranes $(20-40 \mathrm{~cm}$ above the distributor).

The effect of extraction rate is shown in Fig. 14. When comparing the cold flow simulation results with experiments, it is clear that the simulations accurately captured the effect of gas extraction. In both the bubble size and number, the simulations accurately captured the concentration of the bubble stream towards the centre of the bed as the extraction rate was increased. The match for the number of bubbles is especially accurate, while the simulated bubble size appears to be consistently over predicted by the simulations.

Bubble dynamics in the reactive simulations appear to be quite similar to the cold flow simulations. A slight difference appears in higher extraction rates ( $40 \%$ especially) where the bubble distribution appears to be less concentrated in the reactive case. This can be explained by the fact that the extraction rate is constant across the back of the reactor in the cold flow cases, but is proportional to the hydrogen concentration in the reactive case. As shown in Fig. 15, the membrane permeation rate is highest in the centre of the domain where most of the bubbles are rising and lowest at the sides where stagnant zone formation can occur. This phenomenon should reduce the degree to which the bubbles concentrate towards the centre of the domain at higher extraction rates.

The membrane permeation rate was adjusted by a factor of 2.5, 4.0 and 7.5 (C in Eq. (13)) to achieve 20\%, 30\% and $40 \%$ extraction respectively. Doubling the gas extraction from $20 \%$ to $40 \%$ therefore required an increase in membrane permeability of a factor of 3 . This is the result of reduced $\mathrm{H}_{2}$ concentrations and more concentration of $\mathrm{H}_{2}$ towards the centre of the reactor (thus lowering the utilization of the membrane surface area on the sides).
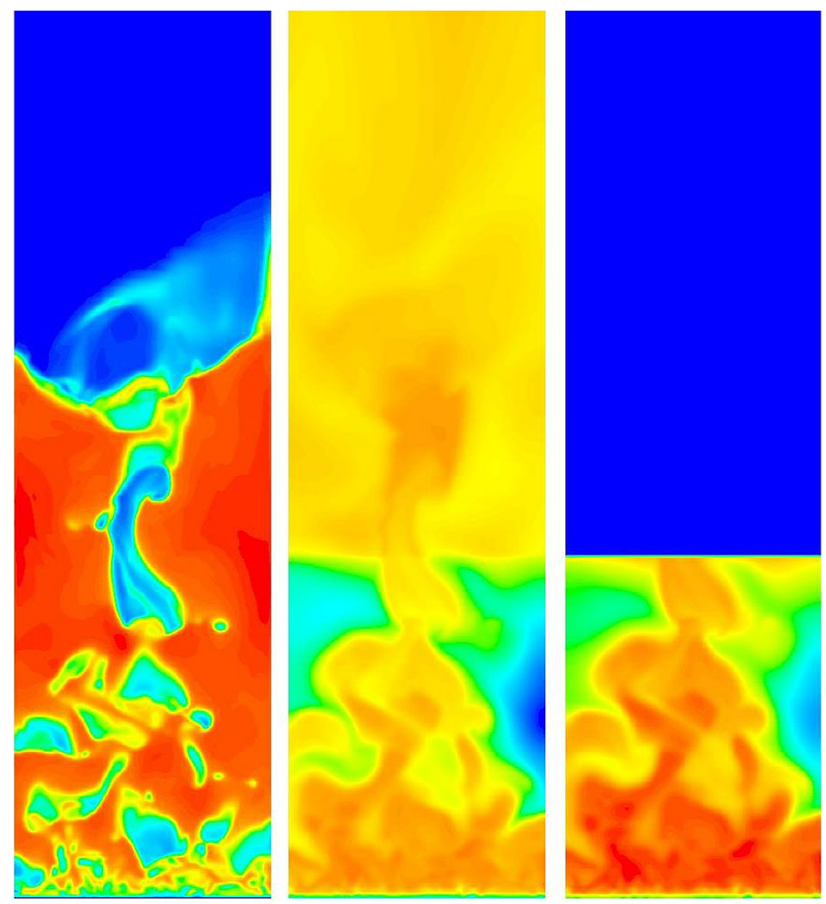

Fig. 15 - Instantaneous contours of solids volume fraction (left), hydrogen mole fraction (middle) and membrane permeation rate (right) in the case with $30 \%$ gas extraction. The ranges in the blue-red colour-maps are as follows: 0-0.6 (left), $0.1-0.5$ (middle) and $0-0.1 \mathrm{~mol} / \mathrm{m}^{2} / \mathrm{s}$ (right). 


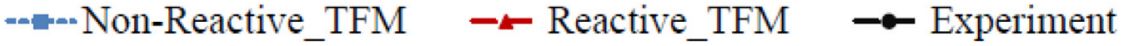
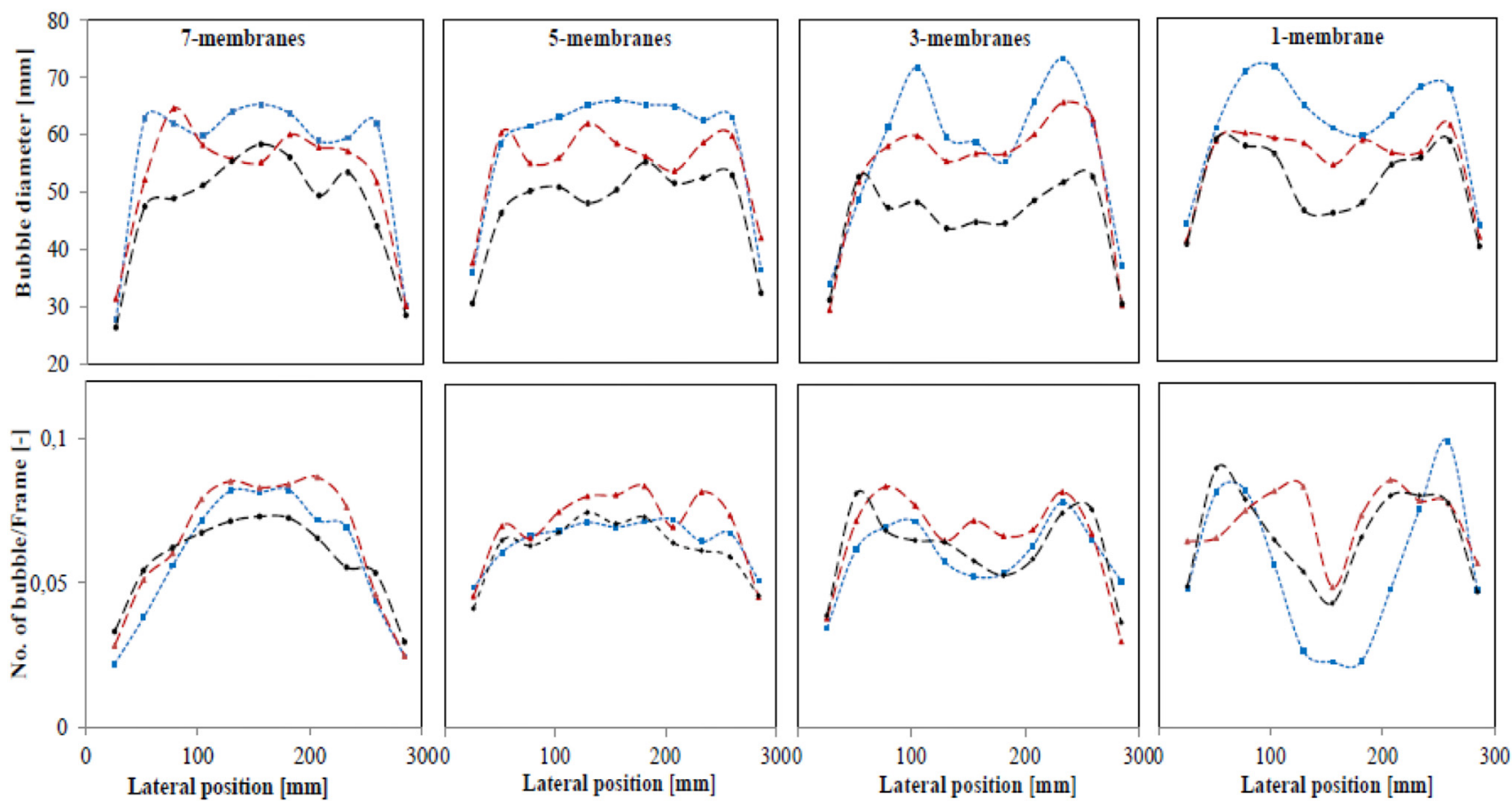

Fig. 16 - Comparison between lateral profiles of bubble size (top) and bubble number (bottom) for the experiments, the coldflow simulations and the reactive simulations for different extraction locations. The lateral profile was averaged over the top half of the membranes $(20-40 \mathrm{~cm}$ above the distributor).

Processed bubble statistics for the cases with varying extraction location are shown in Fig. 16. Similar to the cases with varying extraction rates, the simulations accurately predicted the response of the bubble behaviour to changes in the extraction location, although the bubble size was consistently over predicted. The tendency of the bubble profile to be flatter in reactive simulations (as discussed above) is more pronounced in this case.

The membrane permeation rate was adjusted by a factor of 4.0, 3.8, 4.8 and 20 (C in Eq. (13)) to achieve $30 \%$ gas extraction in the cases with extraction through 7, 5, 3, and 1 membrane respectively. It is interesting to note that slightly less permeable membranes could be used when 5 membranes were employed than in the case of 7 membranes. This implies that a slight improvement in reactor performance can be achieved by reducing the number of vertical membranes from 7 to 5 . Fig. 16 shows why this is the case: it is clear that the bubbles rise more uniformly in the case with 5 membranes than the case with 7 membranes. This more uniform flow reduced gas back-mixing and ensured better contact between the rising hydrogen and the membrane array at the back of the bed.

\section{Summary and conclusions}

This work presented an experimental and numerical study on the effect of vertical membranes on the bubble dynamics in a fluidized bed reactor. The experimental setup was constructed in such a way that the area of extraction could be varied across the back of the setup. This allowed for investigations into the effect of extraction rate and extraction location.

Experimental results showed a relatively small effect of the gas extraction rate across the entire back of the reactor on the bubble size, number and velocity. However, a clear effect of increasing extraction rate was observed in the upper region of the bed where bubbles tended to channel more towards the centre upon increased extraction rates. This was the result of stagnant zone formation on the sides of the geometry forcing the bubbles towards the centre.

Extraction location had a substantially larger impact on the bubble dynamics. When all seven vertical membranes were used, significant channelling towards the centre occurred. Deactivation of the two outer membranes resulted in a substantially more uniform rise of bubbles. If two outer membranes are deactivated on each side, stagnant zones start to form towards the centre, causing bubbles to rise predominantly in two columns at the sides of the bed. Extraction through only one membrane at the centre of the bed further accentuates this effect.

Cold flow simulations successfully reproduced these effects and the methodology could therefore be used to numerically investigate the effect of membrane permeability on reactor hydrodynamics in reactive simulations. In general, trends were the same as observed from the cold flow simulations and experiments. However, the effects of membrane extraction were marginally weaker in the reactive case due to the fact that membrane permeability was proportional to the local hydrogen concentration and not constant at all membranes like in the cold flow studies. 
Regardless of this difference, however, it can be safely concluded that cold flow studies provide a good representation of the hydrodynamic effects that would be observed in a real reactor. As an example, the case with 5 membranes was identified as the optimal case during the experiments due to the high degree of lateral uniformity in the bubble statistics. Reactive simulations then showed that reduction of the number of membranes from 7 to 5 would actually result in a slight increase the amount hydrogen extraction despite the $\sim 30 \%$ reduction in membrane surface area, thereby confirming the experimental conclusion.

\section{Acknowledgement}

The authors would like to acknowledge the financial support of the Research Council of Norway under the FRINATEK (Acronym: CSR, project number: 221902) grant which made this work possible.

\section{R E F E R E N C E S}

[1] IPCC. Climate change: the physical science basis. Cambridge, United Kingdom and New York, NY, USA: Cambridge University Press; 2013. p. 1535.

[2] Adanez Juan, Abad Alberto, Garcia-Labiano Francisco, Gayan Pilar, Luis F. Progress in chemical-looping combustion and reforming technologies. Prog Energy Combust Sci 2012;38(2):215-82.

[3] Gallucci Fausto, Paturzo Luca, Famà Angelo, Basile Angelo. Experimental study of the methane steam reforming reaction in a dense $\mathrm{Pd} / \mathrm{Ag}$ membrane reactor. Ind Eng Chem Res 2004;43(4):928-33.

[4] Rydén M, Lyngfelt A. Using steam reforming to produce hydrogen with carbon dioxide capture by chemical-looping combustion. Int J Hydrogen Energy 2006;31(10):1271-83.

[5] Medrano JA, Spallina V, Annaland M van Sint, Gallucci F. Thermodynamic analysis of a membrane-assisted chemical looping reforming reactor concept for combined $\mathrm{H}_{2}$ production and $\mathrm{CO}_{2}$ capture. Int $\mathrm{J}$ Hydrogen Energy 2014;39(9):4725-38.

[6] Rydén Magnus, Lyngfelt Anders, Schulman Alexander, de Diego Luis F, Adánez Juan, Ortiz María, et al. Developing chemical looping steam reforming and chemical looping autothermal reforming. Carbon dioxide capture for storage in deep geological formations-results from the $\mathrm{CO}_{2}$ capture project. 2009. p. 3.

[7] Eide LI. Carbon dioxide capture for storage in deep geologic formations-results from the $\mathrm{CO}_{2}$ capture project. 2009.

[8] Mattisson T, Lyngfelt A. Applications of chemical-looping combustion with capture of $\mathrm{CO}_{2}$. In: Second nordic minisymposium on $\mathrm{CO}_{2}$ capture and storage, Göteborg, Sweden; 2001.

[9] Rydén M. Hydrogen production from fossil fuels with carbon dioxide capture, using chemical-looping technologies. Chalmers University of Technology; 2008.

[10] Ortiz María, Luis F, Abad Alberto, García-Labiano Francisco, Gayán Pilar, Adánez Juan. Hydrogen production by autothermal chemical-looping reforming in a pressurized fluidized bed reactor using Ni-based oxygen carriers. Int J Hydrogen Energy 2010;35(1):151-60.

[11] Pröll Tobias, Bolhàr-Nordenkampf Johannes, Kolbitsch Philipp, Hofbauer Hermann. Syngas and a separate nitrogen/argon stream via chemical looping reforming-A 140kW pilot plant study. Fuel 2010;89(6):1249-56.

[12] Ortiz María, Abad Alberto, Luis F, García-Labiano Francisco, Gayán Pilar, Adánez Juan. Optimization of hydrogen production by chemical-looping auto-thermal reforming working with Ni-based oxygen-carriers. Int J Hydrogen Energy 2011;36(16):9663-72.

[13] Gallucci F, Annaland MVS, Kuipers J. Autothermal reforming of methane with integrated $\mathrm{CO}_{2}$ capture in a novel fluidized bed membrane reactor. Part 1: experimental demonstration. Topics Catal 2008;51(1-4):133-45.

[14] Wang Junwu, Tan Lianghui, Van der Hoef MA,, van Sint Annaland M, Kuipers JAM. From bubbling to turbulent fluidization: advanced onset of regime transition in microfluidized beds. Chem Eng Sci 2011;66(9):2001-7.

[15] Zaabout Abdelghafour, Cloete Schalk, Johansen Stein Tore, van Sint Annaland Martin, Gallucci Fausto, Amini Shahriar Experimental demonstration of a novel gas switching combustion reactor for power production with integrated $\mathrm{CO}_{2}$ capture. Ind Eng Chem Res 2013;52(39):14241-50.

[16] Cloete Schalk, Romano Matteo C, Chiesa Paolo, Lozza Giovanni, Amini Shahriar. Integration of a gas switching combustion (GSC) system in integrated gasification combined cycles. Int J Greenh Gas Control 2015;42:340-56.

[17] Adris A, Elnashaie S, Hughes R. A fluidized bed membrane reactor for the steam reforming of methane. Can J Chem Eng 1991;69(5):1061-70.

[18] Adris A, Lim CJ, Grace J. The fluidized bed membrane reactor system: a pilot scale experimental study. Chem Eng Sci 1994;49(24):5833-43.

[19] Adris A, Lim C, Grace J. The fluidized-bed membrane reactor for steam methane reforming: model verification and parametric study. Chem Eng Sci 1997;52(10):1609-22.

[20] Grace J, Elnashaie SS, Lim CJ. Hydrogen production in fluidized beds with in-situ membranes. Int J Chem React Eng 2005;3(1).

[21] Patil CS, van Sint Annaland M, Kuipers J. Fluidised bed membrane reactor for ultrapure hydrogen production via methane steam reforming: experimental demonstration and model validation. Chem Eng Sci 2007;62(11):2989-3007.

[22] Chen Zhongxiang, Po Friedrick, Grace John R, Lim C Jim, Elnashaie Said, Mahecha-Botero Andrés, Rakib Mohammad, Shirasaki Yoshinori, Yasuda Isamu. Sorbent-enhanced/ membrane-assisted steam-methane reforming. Chem Eng Sci 2008;63(1):170-82.

[23] Fernandez E, Coenen K, Helmi A, Melendez J, Zuñiga J, Pacheco Tanaka DA, van Sint Annaland M, Gallucci F. Preparation and characterization of thin-film Pd-Ag supported membranes for high-temperature applications. Int J Hydrogen Energy 2015;40(39):13463-78.

[24] Fernandez Ekain, Helmi Arash, Coenen Kai, Melendez Jon, Luis Viviente Jose, Alfredo Pacheco Tanaka David, van Sint Annaland Martin, Gallucci Fausto. Development of thin $\mathrm{Pd}-\mathrm{Ag}$ supported membranes for fluidized bed membrane reactors including WGS related gases. Int J Hydrogen Energy 2015;40(8):3506-19.

[25] Medrano JA, Fernandez E, Melendez J, Parco M, Tanaka DA, van Sint Annaland M, Gallucci F. Pd-based metallic supported membranes: high-temperature stability and fluidized bed reactor testing. Int J Hydrogen Energy 2015 Nov 12;xxx:I-I 3. http://dx.doi.org/10.1016/j.ijhydene.2015.10.094.

[26] De Jong J, van Sint Annaland M, Kuipers J. Experimental study on the effects of gas permeation through flat membranes on the hydrodynamics in membrane-assisted fluidized beds. Chem Eng Sci 2011;66(11):2398-408.

[27] De Jong J, van Sint Annaland M, Kuipers J. Experimental study on the hydrodynamic effects of gas permeation 
through horizontal membrane tubes in fluidized beds. Powder Technol 2013;241:74-84.

[28] Asegehegn TW, Schreiber M, Krautz HJ. Investigation of bubble behavior in fluidized beds with and without immersed horizontal tubes using a digital image analysis technique. Powder Technol 2011;210(3):248-60.

[29] Julián I, Gallucci F, van Sint Annaland M, Herguido J, Menéndez M. Hydrodynamic study of a two-section twozone fluidized bed reactor with an immersed tube bank via PIV/DIA. Chem Eng Sci 2015;134:238-50.

[30] Medrano JA, Voncken RJ, Roghair I, Gallucci F, van Sint Annaland M. On the effect of gas pockets surrounding membranes in fluidized bed membrane reactors: an experimental and numerical study. Chem Eng J 2015;282:45-57.

[31] Deshmukh S, van Sint Annaland M, Kuipers J. Effect of fluidization conditions on the membrane permeation rate in a membrane assisted fluidized bed. Chem Eng J 2003;96(1):125-31.

[32] Deshmukh SARK, Laverman Jan Albert, Cents AHG, van Sint Annaland M, Kuipers JAM. Development of a membraneassisted fluidized bed reactor. 1. Gas phase back-mixing and bubble-to-emulsion phase mass transfer using tracer injection and ultrasound experiments. Ind Eng Chem Res 2005;44(16):5955-65.

[33] Deshmukh S, van Sint Annaland M, Kuipers J. Gas backmixing studies in membrane assisted bubbling fluidized beds. Chem Eng Sci 2007;62(15):4095-111.

[34] Dang NT, Gallucci F, van Sint Annaland M. Micro-structured fluidized bed membrane reactors: solids circulation and densified zones distribution. Chem Eng J 2014;239:42-52.

[35] Dang T, Gallucci F, van Sint Annaland M. Gas mixing study in freely bubbling and turbulent gas-solid fluidized beds with a novel infrared technique coupled with digital image analysis. Chem Eng Sci 2014;116:38-48.

[36] Dang T, Gallucci F, van Sint Annaland M. Gas back-mixing study in a membrane-assisted micro-structured fluidized bed. Chem Eng Sci 2014;108:194-202.

[37] Tan L, Roghair I, van Sint Annaland M. Simulation study on the effect of gas permeation on the hydrodynamic characteristics of membrane-assisted micro fluidized beds. Appl Math Model 2014;38(17-18):4291-307.

[38] Gallucci Fausto, Fernandez Ekain, Corengia Pablo, van Sint Annaland Martin. Recent advances on membranes and membrane reactors for hydrogen production. Chem Eng Sci 2013;92:40-66.

[39] Peters T, Stange M, Bredesen R. On the high pressure performance of thin supported $\mathrm{Pd}-23 \% \mathrm{Ag}$ membranes-evidence of ultrahigh hydrogen flux after air treatment. J Membr Sci 2011;378(1):28-34.

[40] Lim K, Agarwal P, O'neill B. Measurement and modelling of bubble parameters in a two-dimensional gas-fluidized bed using image analysis. Powder Technol 1990;60(2):159-71.

[41] Lim K, Agarwal PK. Conversion of pierced lengths measured at a probe to bubble size measures: an assessment of the geometrical probability approach and bubble shape models. Powder Technol 1990;63(3):205-19.

[42] Lim KS, Gururajan VS, Agarwal PK. Mixing of homogeneous solids in bubbling fluidized beds: theoretical modelling and experimental investigation using digital image analysis. Chem Eng Sci 1993;48(12):2251-65.

[43] Hull AS, Chen Z, Agarwal PK. Influence of horizontal tube banks on the behavior of bubbling fluidized beds: 2. Mixing of solids. Powder Technol 2000;111(3):192-9.

[44] Hull Ashley S, Chen Zumao, Fritz Jack W, Agarwal Pradeep K. Influence of horizontal tube banks on the behavior of bubbling fluidized beds: 1 . Bubble hydrodynamics. Powder Technol 1999;103(3):230-42.
[45] Laverman Jan Albert, Roghair Ivo, Sint Annaland Martin van, Kuipers Hans. Investigation into the hydrodynamics of gas-solid fluidized beds using particle image velocimetry coupled with digital image analysis. Can J Chem Eng 2008;86(3):523-35.

[46] Shen L, Johnsson F, Leckner B. Digital image analysis of hydrodynamics two-dimensional bubbling fluidized beds. Chem Eng Sci 2004;59(13):2607-17.

[47] Goldschmidt MJV, Link JM, Mellema S, Kuipers JAM. Digital image analysis measurements of bed expansion and segregation dynamics in dense gas-fluidised beds. Powder Technol 2003;138(2):135-59.

[48] Busciglio A, Vella G, Micale DG. Gas-fluidization characteristics of binary mixtures of particles in 2D geometry. Int J Chem React Eng 2012;10(1).

[49] Caicedo Guadalupe Ramos, Marqués Juan J Prieto, Ruız Mónica Garcia, Soler Jesús Guardiola. A study on the behaviour of bubbles of a 2D gas-solid fluidized bed using digital image analysis. Chem Eng Process Process Intensif 2003;42(1):9-14.

[50] Cloete S, Amini S, Johansen ST. On the effect of cluster resolution in riser flows on momentum and reaction kinetic interaction. Powder Technol 2011;210(1):6-17.

[51] Syamlal M, Rogers W, O'Brien T. MFIX documentation: volume 1, theory guide. Springfield, VA: National Technical Information Service; 1993. There is no corresponding record for this reference.

[52] Van Wachem BGM, Schouten JC, Van den Bleek CM, Krishna R, Sinclair JL. Comparative analysis of CFD models of dense gas-solid systems. Am Inst Chem Eng AIChE J 2001;47(5):1035.

[53] Lun CKK, Savage SB, Jeffrey DJ, Chepurniy N. Kinetic theories for granular flow: inelastic particles in Couette flow and slightly inelastic particles in a general flowfield. J Fluid Mech 1984;140:223-56.

[54] Gidaspow D, Bezburuah R, Ding J. Hydrodynamics of circulating fluidized beds: kinetic theory approach. Illinois Inst. of Tech., Chicago, IL (United States): Dept. of Chemical Engineering; 1991.

[55] Schaeffer DG. Instability in the evolution equations describing incompressible granular flow. J Differ Equ 1987;66(1):19-50.

[56] Ogawa S, Umemura A, Oshima N. On the equations of fully fluidized granular materials. Z für Angew Math Phys ZAMP 1980;31(4):483-93.

[57] Johnson PC, Jackson R. Frictional-collisional constitutive relations for granular materials, with application to plane shearing. J Fluid Mech 1987;176:67-93.

[58] Cloete S, Johansen ST, Amini S. An assessment of the ability of computational fluid dynamic models to predict reactive gas-solid flows in a fluidized bed. Powder Technol 2012;215:15-25.

[59] Xu J, Froment GF. Methane steam reforming, methanation and water-gas shift: I. Intrinsic kinetics. AIChE J 1989;35(1):88-96.

[60] Oliveira EL, Grande CA, Rodrigues AE. Methane steam reforming in large pore catalyst. Chem Eng Sci 2010;65(5):1539-50.

[61] Zhou Z, Han L, Bollas GM. Model-based analysis of benchscale fixed-bed units for chemical-looping combustion. Chem Eng J 2013;233:331-48.

[62] Gallucci F, Annaland MVS, Kuipers J. Autothermal reforming of methane with integrated $\mathrm{CO}_{2}$ capture in a novel fluidized bed membrane reactor. Part 2 comparison of reactor configurations. Top Catal 2008;51(1-4):146-57.

[63] Patankar S. Numerical heat transfer and fluid flow. CRC Press; 1980.

[64] Leonard B, Mokhtari S. ULTRA-SHARP nonoscillatory convection schemes for high-speed steady multidimensional flow. 1990. 